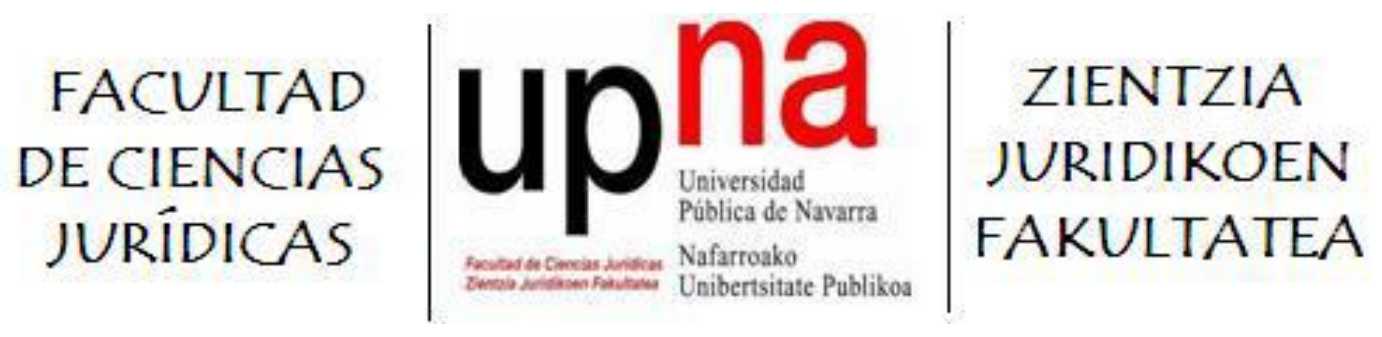

TRABAJO FIN DE MÁSTER / MASTER AMIERAKO LANA

\title{
LA NECESARIA REFORMA DE LA LEY FORAL DE TURISMO DE NAVARRA A LA LUZ DE LA DIRECTIVA DE SERVICIOS
}

Ignacio Ordoki Guarch

DIRECTOR / ZUZENDARIA

Martín María Razquin Lizarraga

$$
\text { Pamplona / Iruñea }
$$

18 de enero de 2016/ 2016ko urtarrilaren 18a 


\section{ÍNDICE}

\section{I.- INTRODUCCIÓN}

1.- La creciente importancia económica y social del sector turístico. 3

2.- El sector turístico de la Comunidad Foral de Navarra en cifras y su importancia como futuro factor de desarrollo económico y social.......... 4

\section{II.- LA DIRECTIVA DE SERVICIOS (DS)}

1.- Contexto en el que se enmarca la Directiva de Servicios 5

2.- Concepto de "servicios" y la novedad de esta Directiva................ 9

3.- Objetivos, líneas de actuación y contenido de la Directiva............. 11

3.1 Objetivos................................................. 11

3.2 Líneas de actuación............................................. 11

3.3 Contenido................................................... 12

4.- Problemas que ha planteado su aplicación.......................... 14

4.1 Principio de país de origen..................................... 15

4.2 El método horizontal que adopta la DS......................... 16

4.3 Eliminación de controles previos como exponente de la liberalización del sector servicios

\section{III.- LA INCORPORACIÓN DE LA DS AL DERECHO INTERNO}

1.- Transposición de la DS en el ámbito estatal. 18

1.1 El proceso español de transposición: una cuestión compleja........ 18

1.2 La Ley 17/2009, transposición de carácter horizontal............. 20

1.3 La Ley 25/2009, transposición de carácter vertical............... 22

2.- Transposición de la DS en la Comunidad Foral ........................ 24

2.1 La Ley Foral 15/2009, transposición de carácter trasversal....... 24

2.2 La Ley Foral 6/2010, transposición de carácter sectorial........... 25

3.- La transposición de la DS como un proceso dinámico que debe profundizarse y aplicarse en el tiempo................................ 26 


\section{IV.- MARCO JURÍDICO REGULADOR DEL TURISMO EN NAVARRA}

1.- La situación anterior a la entrada en vigor de la Directiva.............. 26

2.- Regulación del turismo en Navarra tras la transposición de la DS..... 28

3.- El cambio de modelo en el ejercicio de actividades turísticas: de la autorización administrativa previa a la declaración responsable......... 31

4.- La declaración responsable en el ordenamiento jurídico estatal y foral 33

4.1 La figura de la declaración responsable.......................... 33

4.2 Su regulación en el nuevo artículo 71 bis de la Ley 30/1992 ........ 34

4.3 La declaración responsable en LF 15/2009, de 9 de diciembre...... 37

4.4 La declaración responsable en legislación turística de Navarra.... 38

5.- Reflexiones sobre la transposición de la DS Navarra en el ámbito del turismo

V.- NECESIDAD DE ACTUALIZAR EL MARCO JURÍDICO REGULADOR DEL TURISMO EN NAVARRA PARA SU PLENA ADAPTACIÓN A LA DS: LÍNEAS DE ACTUACIÓN PARA SU REFORMA

1.- El turismo como una realidad poliédrica cuya regulación debe ir más allá de su consideración de mera actividad económica.

2.- La regulación detallada del inicio de la actividad turística y de la inscripción en el Registro de Turismo de Navarra. 43

3.- La oportunidad de recuperar la autorización previa en el caso de actividades turísticas que afecten notoriamente al interés general......... 45

4.- La implantación de mecanismos eficaces de supervisión posterior..... 46

5.- Información y formación de los operadores turísticos................ 48

6.- Apuesta por la calidad, el turismo sostenible $y$ el enfoque hacia el usuario de los servicios turísticos

7.- Apuesta por la administración electrónica y la simplificación administrativa........................................................ 51

8.- Cooperación y coordinación entre administraciones públicas.......... 52

9.- Respuesta a los nuevos retos y realidades del sector turístico........... 53

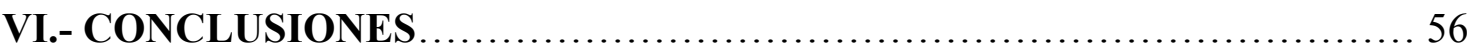




\section{INTRODUCCIÓN}

\section{La creciente importancia económica y social del sector turístico}

El turismo es un sector en creciente expansión a nivel mundial, europeo y nacional como lo acreditan diversos estudios de la Organización Mundial del Turismo (en adelante OMT). En su informe anual de 2014 y en su informe de perspectivas sobre el turismo internacional, edición 2014, la OMT destaca que el turismo en el mundo ha superado con creces para el año 2014 las expectativas de crecimiento, con un incremento del 4,4\%, obteniendo cifras de record hasta alcanzar los 1.135 millones de turistas y los 937 billones de euros de ingresos a nivel mundial, consolidando una serie de 5 años de crecimiento por encima de las previsiones y, ello, a pesar de la crisis económica y de los grandes desafíos pendientes que debe superar el sector.

Este crecimiento es aún mayor en Europa, que capta el 51\% del turismo mundial, y es aún más significativo en los países del área mediterránea europea, entre los que destaca España, como primer destino turístico de esta subregión Europea, con incrementos cercanos al 7\% anual. Estos informes resaltan también que las perspectivas futuras a medio y largo plazo son muy positivas, con crecimientos medios esperados hasta el año 2030, en torno al 4\% para el conjunto de Europa y superiores en los países del sur y del área mediterránea, constituyendo para estos países un sector clave para el desarrollo, la superación de la crisis y la recuperación económica ${ }^{1}$.

El informe "Panorama OMT del turismo internacional 2014", señala que la llegada de turistas internacionales a España, ha pasado de los 52,2 millones registrada en 2010, a los 60,6 millones registrados en 2013. Según datos del Gobierno Español, el número de turistas registrados en 2014, ascendió a los 65 millones, existiendo unas previsiones de alcanzar los 68 millones en 2015, lo que representa un incremento superior al 30\% en estos últimos cinco años.

En España, el sector turístico constituye un activo fundamental para la creación de riqueza, supone más del 10,2\% del PIB nacional y el 11,39\% del empleo. Es un sector que, como se afirma en el Plan Nacional e Integral de Turismo 2012-2015 (PNIT), "se comporta con gran dinamismo incluso en tiempos de crisis y que cuenta con una gran capacidad de arrastre de otros sectores productivos". Un sector, en definitiva, que sitúa a España como el primer destino turístico del mundo en turismo vacacional, el segundo

\footnotetext{
${ }^{1}$ Datos extraídos de “Annual Report 2014 of World Tourism Organization” (UNWTO), págs. 10-13 y del Informe Panorama OMT del turismo internacional, edición 2014.
} 
por ingresos (60.000 millones de dólares) y el tercero en términos de llegadas de turistas, tan solo por detrás de EEUU y muy cerca de Francia ${ }^{2}$.

\section{El sector turístico de la Comunidad Foral de Navarra en cifras y su importancia como futuro factor de desarrollo económico y social}

Los datos anteriores ponen de relieve la importancia del sector turístico en España y las perspectivas favorables de crecimiento en los próximos años, previsiones plenamente extensibles a Navarra que está viendo, en los últimos años, un incremento constante en la llegada de turistas y en los ingresos que reporta este sector.

Según el Plan Estratégico del Turismo en Navarra (en adelante, PETN) para el periodo 2012-2015, este sector supone entre el 5 y 6\% del PIB de la Comunidad Foral, en Pamplona en torno al 8\%. Da empleo a más de 30.000 personas, que supone el 14\% del total de la población activa en servicios y el 8,8\% de la población activa en Navarra. Según la Cámara Navarra de Comercio e Industria, el tejido empresarial que produce servicios relacionados con el turismo integra a 3.386 empresas y 30.908 trabajadores.

Según los datos del PETN, la mayor parte del turismo en Navarra es nacional, procediendo del País Vasco, Madrid y Cataluña más del 50\% del total de visitantes. Alemania y Francia son los países que aportan un mayor número de visitantes, si bien su porcentaje es pequeño en comparación con el turismo nacional. Los datos reflejan que la Comunidad Foral tiene alta dependencia del turismo nacional y un bajo peso del turismo internacional, por lo que hay un notable potencial de crecimiento en este sector.

En cuanto al número de alojamientos turísticos, Navarra ha pasado de los 848 alojamientos censados en 2003 a 1.384 contabilizados en 2011, con un total de 34.071 plazas, y unos incrementos anuales superiores al 5\%, que se estima seguirán creciendo en los próximos años ${ }^{3}$. Según datos de agosto de 2015, el número de alojamientos turísticos registrados en el Gobierno de Navarra, se acerca a los $1.900^{4}$.

Como datos recientes, referidos a 2014, el número de turistas alcanzó en Navarra la cifra de 1.183 .520 con un incremento del 9\% respecto de los datos de 2013, sólo por detrás de la Comunidad de Madrid, suponiendo un 6\% del PIB de Navarra ${ }^{5}$. En el

\footnotetext{
${ }^{2}$ Vid. PÉREZ FernándeZ, J.M. "Directiva de servicios y turismo: el nuevo régimen de acceso y prestación de los servicios turísticos y su contribución al incremento de la calidad turística", en Revista de Derecho de la Unión Europea, núm. 24, 2013, págs. 257-318.

${ }^{3}$ Los datos de Navarra, tomados del Plan Estratégico de Navarra año 2012-2015, son estimativos.

${ }^{4}$ Información recogida del portal InfoReyno de Turismo del Gobierno de Navarra.

${ }^{5}$ Vid. Diario de Noticias, de 21 de febrero de 2015, con motivo de la presentación en Baluarte de la décima edición de Navartur.
} 
primer semestre de 2015, 523.000 viajeros han hecho uso de los establecimientos turísticos de Navarra, lo que supone un 3,3\% más que el mismo período de 2014. Aunque 3 de cada 4 viajeros eran españoles, el turismo extranjero es el que más crece con un incremento del 11,2\%. Por alojamientos, destaca el aumento en apartamentos $(35,2 \%)$ y casas rurales $(26 \%)$, mientras que los hoteles aumentaron un $2,8 \%{ }^{6}$.

Sirvan estos datos para resaltar, la importancia que desde el punto de vista económico tiene el turismo en la Comunidad Foral que, previsiblemente, seguirá creciendo en los próximos años. En todo caso, junto al aspecto económico, la actividad turística conlleva también relevantes consecuencias desde el punto de vista social, cultural, de defensa del patrimonio y del entorno natural, así como un enriquecimiento y e intercambio de ideas que pueden ser de gran utilidad para el crecimiento de esta Comunidad. A ello también cabría añadir, que puede llegar a contribuir al arraigo de las personas en su entorno geográfico, así como al equilibrio territorial de Navarra.

En consecuencia, vista la importancia y el potencial de crecimiento de este sector, los poderes públicos deben dotarse de un marco regulador en materia turística que persiga un equilibrio entre el desarrollo económico y los intereses generales de carácter medioambiental, cultural, social y defensa de los consumidores y usuarios en juego. Este marco jurídico debe dar respuesta también a las nuevas realidades que surgen en este ámbito y todo ello, por supuesto, a la luz de las directivas comunitarias y, en especial, de la Directiva de Servicios 2006/123/CE (en adelante DS), que pretende un objetivo similar de estimular el desarrollo económico en el ámbito de los servicios, creando un verdadero mercado único interior.

\section{LA DIRECTIVA DE SERVICIOS (DS)}

\section{Contexto en el que se enmarca la Directiva de Servicios}

La Directiva de Servicios 2006/123/CE se enmarca en la denominada "Estrategia de Lisboa", impulsada por el Consejo Europeo a partir del año 2000, que marcó el ambicioso objetivo de convertir la economía de la Unión Europea, antes del año 2010, en la "economía del conocimiento más competitiva y dinámica del mundo, capaz de un crecimiento económico duradero acompañado por una mejora cuantitativa y cualitativa

\footnotetext{
${ }^{6}$ Vid. Diario de Noticias, del 6 de agosto del año 2015, relativo al número de visitantes que se alojaron en Navarra en el primer semestre.
} 
del empleo y de una mayor cohesión social"7. Éste objetivo, que se manifestó en otras muchas medidas políticas y jurídicas se materializa, en el caso de los servicios, a través de esta norma comunitaria ${ }^{8}$.

El mercado común, principal objetivo del Tratado de Roma de 1958, ya pretendía eliminar las barreras al comercio entre los Estados con el objetivo de incrementar la prosperidad económica y contribuir a "una unión cada vez más estrecha entre los pueblos europeos". Fue construyéndose a través de la unión aduanera de 1968, la eliminación de las cuotas, la libre circulación de ciudadanos y trabajadores, y cierta armonización fiscal conseguida en 1970 mediante la implantación generalizada del IVA. No obstante, el libre comercio de mercancías y servicios y la libertad de establecimiento seguían estando limitados debido a la persistencia de prácticas anticompetitivas y barreras diversas impuestas por las autoridades públicas nacionales ${ }^{9}$.

La falta de avances en la consecución del mercado común llevó a mediados de los 80 a la Comunidad Económica Europea (CEE) a buscar un enfoque más riguroso para lograr la supresión de las barreras comerciales: el mercado interior ${ }^{10}$. El Acta Única Europea de 1987, incluyó en el Tratado constitutivo de la CEE el objetivo de lograr un mercado interior ${ }^{11}$ antes del 31 de diciembre de 1992. El principio de que los bienes, servicios, capitales y trabajadores circulen libremente entre los Estados miembros, es una piedra angular de la UE y su plena aplicación clave para lograr el mercado interior.

Debe destacarse que el sector servicios es el más importante de la economía europea en términos de economía y empleo y el que ha experimentado un mayor desarrollo en los últimos años. A esta expansión ha contribuido el Tratado de la Comunidad Europea que consagró, ya en 1957, tanto la libertad de establecimiento como la libre circulación de servicios dentro de la Unión (arts. 43 y 49 TCE). Sin

\footnotetext{
${ }^{7}$ Véase al respecto el punto quinto del documento "Conclusiones de la Presidencia del Consejo Europeo de Lisboa” accesible en http://www.europarl.europa.eu/summits/lis1_es.htm.

${ }^{8}$ Vid. Villarejo Galende, H. y Salvador ARMEndáriz, M.A. "El complejo proceso de transposición de la Directiva de Servicios", en Revista informe Comunidades Autónomas, núm. 2008, 2008, págs. 81 y ss.

${ }^{9}$ Idea recogida en la Página Web www.europarl.europa.eu/ftu/pdf/es/FTU_3.1.1.pdf "Mercado interior: principios generales", págs.1-5, que recoge diversas fichas técnicas sobre la Unión Europea, publicadas por la Comisión.

${ }^{10}$ Idea recogida en la Página Web www.europarl.europa.eu/ftu/pdf/es/FTU_3.1.1.pdf "Mercado interior: principios generales", pags.1-5, que recoge diversas fichas técnicas sobre la Unión Europea, publicadas por la Comisión.

${ }^{11}$ El Tratado Constitutivo de la Comunidad Europea, definió en su art. 14.2 el mercado interior como "un espacio sin fronteras interiores, en el que la libre circulación de mercancías, personas, servicios y capitales estará garantizada". Su objetivo era superar el objetivo del Mercado Común (que en esencia significó una Europa sin aranceles aduaneros), para alcanzar un objetivo de mayor integración empresarial y económica en el Mercado Interior.
} 
embargo, tras cuatro décadas de Tratado, los avances en estas libertades, que seguían un enfoque sectorial, se revelaban insuficientes ${ }^{12}$ y para las instituciones comunitarias, el mercado interior de los servicios "no funcionaba como debería"13.

Ante este escenario, la Estrategia de Lisboa supuso un gran cambio en el enfoque seguido hasta entonces. En el espacio europeo la libre circulación de mercancías, capitales y trabajadores era una realidad, pero no estaba garantizada en toda su plenitud la libertad de establecimiento y de prestación de servicios, y ésta será la pretensión esencial de la DS, lograr un verdadero mercado interior de los servicios ${ }^{14}$.

Para ello, en la Cumbre de Lisboa de marzo de 2000, el Consejo Europeo instó a la Comisión Europea a elaborar un informe ${ }^{15}$ sobre la situación del mercado interior de servicios, que identificara las principales barreras y obstáculos para la consecución de dicho mercado, así como posibles soluciones ${ }^{16}$. Como respuesta la Comisión definió, en diciembre de 2000 , una estrategia de conjunto ${ }^{17}$ para el mercado interior de servicios que recibió el apoyo unánime de los Estados, del Parlamento Europeo, del Comité Económico y Social y del Comité de Regiones. La estrategia tiene como objetivo permitir que los servicios puedan prestarse a través de la UE con la misma facilidad que dentro de un Estado miembro.

En el año 2002 la Comisión publicó su informe sobre el "El estado del mercado interior de servicios ${ }^{18}$, , donde llegaba a la conclusión de que diez años después de lo

${ }^{12}$ El documento del Ministerio de Hacienda y Administraciones Públicas, ¿Por qué una Directiva de Servicios? afirma lo siguiente: "La fragmentación existente en el mercado interior de servicios continuaba repercutiendo de forma negativa en el crecimiento de la economía europea y, particularmente, en la creación de empleo y en la competitividad de la Pequeña y Mediana Empresa (PYME), al tiempo que impedía que los consumidores accedieran a una mayor variedad de servicios a menores precios", accesible en http://www.minhap.gob.es/.

${ }^{13}$ Vid. Villarejo Galende, H. y Salvador ArmendáRiz, M.A. "El complejo proceso de transposición de la Directiva de Servicios", cit., pág. 81 señala "de acuerdo con la Comisión, la mayoría de los beneficios del mercado interior han tenido lugar en el mercado de bienes y se hacía necesario mejorar el funcionamiento del mercado interior de servicios. Así puede leerse en el sitio de la Comisión Europea sobre el Mercado Único: http:// ec.europa.eu/internal_market/top_layer/index_19_en.htm.

${ }^{14}$ Se trata de una propuesta doctrinal reiterada. A título de ejemplo, Vid. JIMÉNEZ ÂSENSIO, R. La incorporación de la DS al Derecho interno. IVAP, Oñati, 2010, pág. 27.

${ }^{15}$ Debe subrayarse que las conclusiones del Consejo Europeo de Lisboa no hacían referencia a una Directiva "general" de servicios, únicamente requerían "una estrategia para remover las barreras a los servicios". La idea de una Directiva general, de enfoque horizontal, aparece por primera vez en el documento "Estrategia para un mercado interior de los servicios", presentado por la Comisión el 29 de Diciembre de 2000 [COM (2000) 888].

${ }^{16}$ Vid. Documento del Ministerio de Hacienda y Administraciones Públicas, ¿Por qué una Directiva de Servicios?

${ }^{17}$ Véase la Comunicación de la Comisión al Consejo y al Parlamento Europeo, Una estrategia para el mercado interior de servicios, COM (2000) 888 final, 9.12.2000.

${ }^{18}$ Conforme a la labor encomendada por el Consejo, la Comisión dicta el Informe de la Comisión al Consejo y al Parlamento Europeo sobre "El estado del mercado interior de servicios" [COM (2002) 441 final, de 30 de julio]. 
que debería haber sido la realización del mercado interior, existían todavía numerosas barreras por lo que no podía hablarse de un mercado único de servicios ${ }^{19}$. El enfoque sectorial seguido hasta entonces resultaba insuficiente para abarcar todas las actividades del sector servicios. El informe analiza la diversidad de normas y prácticas que rigen la prestación de los servicios en los Estados miembros y constata que, por su variedad y número, constituyen un obstáculo al desarrollo del mercado interior de servicios ${ }^{20}$.

En este contexto, la configuración de un verdadero mercado interior de servicios debía hacerse adoptando un enfoque global y horizontal y no a través de directivas sectoriales parciales, de manera que una única directiva abordara la eliminación de las barreras que restringen el acceso y el ejercicio de las actividades de servicios en la UE.

Tras su informe, la Comisión Europea elaboró una propuesta de Directiva, publicada el 13 de enero de 2004, que fue revisada por el Parlamento y el Consejo Europeos y consensuada con los agentes involucrados. Finalmente, tras casi tres años de tramitación, el Consejo aprobó definitivamente en diciembre de 2006 la Directiva 2006/123/CE, del Parlamento Europeo y del Consejo, relativa a los servicios en el mercado interior, más conocida como Directiva de Servicios o Directiva Bolkestein, que fue publicada en el Diario Oficial de la Unión Europea, el 13 de diciembre ${ }^{21}$.

La DS se enmarca en la liberalización económica propugnada por la $\mathrm{UE}^{22}$ y es una de las piezas clave de la Estrategia comunitaria de impulso económico y consolidación

\footnotetext{
${ }^{19}$ Vid. JimÉneZ ASEnsio, R. La incorporación de la DS al Derecho interno, cit., pág. 35 destaca "el informe es un documento muy importante en la medida en que supuso la primera reflexión en profundidad que dará pie al proceso de elaboración de la DS. De hecho, la mayor parte de los análisis que se han realizado de la propia directiva han hecho hincapié en mayor o menor medida en este documento". Véase también el Informe COM (2002) 441 final de la Comisión al Consejo y al Parlamento Europeo pág. 14 se señala que "este informe constituye un documento esencial en el proceso de creación de un verdadero mercado interior de servicios, al presentar una visión de conjunto de la realidad del mercado interior y efectuar un análisis de todas las dificultades existentes".

${ }^{20}$ Vid. EsTEVE GARCÍA, F. "Els diferents instruments de liberalitzazió inclosos en la Directiva 2006/123 de serveis", en Revista catalana de dret públic, núm. 42, 2011, pág. 6.

${ }^{21}$ Véase Villarejo Galende, H. y SAlvador ARMEndÁRiz, M.A. "El complejo proceso de transposición de la Directiva de Servicios", cit., págs. 82 y ss. señala que "el Parlamento Europeo terminó aprobando en diciembre de 2006 una versión suavizada del controvertido borrador presentado en enero de 2004 por la Comisión. (...) Merced al rechazo y la resistencia generada, su proceso de aprobación se vio interrumpido en varias ocasiones. Finalmente las enmiendas introducidas por el Parlamento Europeo transformaron la propuesta inicial de la Directiva Bolkestein y desde el punto de vista técnico, éstas han dado lugar a un texto defectuoso, con numerosas contradicciones y ciertas ambigüedades".

${ }^{22}$ Esta liberalización conlleva la adopción de medidas tendentes a dinamizar la vida económica y que consisten en la eliminación por parte de la Administración de las restricciones y limitaciones que afectan al libre desarrollo empresarial. Las modalidades pueden ser diversas, en el ámbito de turismo que nos ocupa, un ejemplo seria la sustitución de la técnica de autorización por otras menos restrictivas.
} 
del mercado interior diseñada por la estrategia de Lisboa $^{23}$. Su aplicación constituye no sólo una obligación en tanto que Derecho comunitario derivado, sino también una oportunidad para reformar en profundidad un sector de gran importancia para la economía comunitaria y desbloquear el potencial del sector servicios en Europa ${ }^{24}$.

El Consejo Europeo de diciembre de 2009 propuso revisar la Estrategia de Lisboa tomando como punto de partida el impacto de la crisis y los retos futuros que se plantean. Consecuencia de esta revisión, la Comisión propuso una estrategia política sucesora de la Estrategia de Lisboa que expiró en 2010, denominada «Europa 2020».

\section{Concepto de "servicios" y la novedad de esta Directiva}

Como norma básica, la DS se aplica a todos los servicios que no se excluyan específicamente de su ámbito. De conformidad con el artículo 57 del TFUE y la jurisprudencia del TJUE, se define servicio de un modo amplio, como toda actividad económica por cuenta propia realizada normalmente a cambio de una remuneración.

Con arreglo al TFUE y a la DS, para que una actividad constituya un servicio, ha de realizarse por cuenta propia, por un prestador (persona física o jurídica), al margen de un contrato de trabajo, a cambio de una remuneración. La característica esencial reside en que la remuneración sea contrapartida económica de la prestación del servicio, siendo irrelevante que sea abonada por el destinatario del servicio o por un tercero.

La DS, en su art. 2.1, señala que se aplicará a los servicios prestados, por los prestadores establecidos en un Estado miembro, indicando el apartado segundo los servicios excluidos de su aplicación. Es decir, la DS formula el concepto de servicios sujetos en términos muy amplios, extendiendo su aplicación a todos aquellos que no estén expresamente excluidos.

Como servicios contemplados en el considerando 33 de la DS, podemos señalar las actividades de la mayoría de los profesionales reguladas, las tareas de distribución, los servicios de información, los servicios en el área de la formación y la educación, los servicios inmobiliarios $\mathrm{y}$, por lo que al objeto de este trabajo interesa, los servicios turísticos, que incluyen los prestados por agencias de viaje, los servicios de alojamiento y restauración, y los servicios relacionados con el ocio, entre otros.

\footnotetext{
${ }^{23}$ Véase. Fernández Barjau, B. y Martínez Albaladejo, T. "El proceso de transposición de la Directiva de Servicios en España”, en Boletín económico de ICE, Información Comercial Española, núm. 2990, 2010, págs. 5-14.

${ }^{24}$ He tomado esta afirmación de la Exposición de motivos de la Ley Foral 6/2010, de 6 de abril.
} 
Por el contrario, del ámbito de aplicación de la DS se excluyen, entre otros, los servicios no económicos de interés general, los financieros, los servicios y redes de comunicaciones electrónicas, los de transporte, los sanitarios, los audiovisuales y de difusión, los vinculados al ejercicio de la autoridad pública, los servicios sociales y los de seguridad privado. Aunque estos servicios quedan excluidos de la DS, debe destacarse que quedan sujetos a los principios de libertad de establecimiento y de libre prestación de servicios, consagrados en los arts. 49 y 56 del TFUE ${ }^{25}$.

La novedad de la DS, radica en que la "liberalización" de los servicios que hasta la fecha, se había hecho por sectores (telecomunicaciones, servicios postales etc.) se plantea ahora, con carácter general ${ }^{26}$. La DS, tiene un carácter horizontal muy amplio, extendiéndose a todos los servicios que no estén expresamente excluidos por la misma.

La DS ha introducido en su regulación una serie de preceptos que hacen que la “desregulación” sea una de las notas características de este instrumento normativo. Pretende impulsar la apertura y la libre competencia, obligando a los Estados a eliminar o cuanto menos reducir, las trabas establecidas en forma de trámites y requisitos procedimentales y sustantivos. Por tanto es una norma que, con efectos desreguladores, rediseña y controla la regulación nacional de las actividades económicas. Al mismo tiempo, codifica varios principios jurisprudenciales, incluyendo una cierta armonización de algunas prohibiciones y de algunas obligaciones generales. Finalmente, es una Directiva de coordinación que requiere a los Estados para que trabajen en cooperación entre ellos, así como con la Comisión en la mejora de la calidad de los servicios ${ }^{27}$.

Por todo ello, la DS es uno de los instrumentos legislativos más singulares y novedosos aprobados en los últimos tiempos y, seguramente, por su incidencia en los ordenamientos jurídicos de los Estados, la norma más importante aprobada por la $\mathrm{UE}^{28}$.

\footnotetext{
${ }^{25}$ COMISIÓN “Manual sobre la Transposición de la Directiva de Servicios”, año 2007, ámbito de aplicación de la Directiva, págs. 10-14.

${ }^{26}$ Véase Villarejo Galende, H. y SAlvador ARMendáRiz, M.A. "El complejo proceso de transposición de la Directiva de Servicios”, cit., pág. 91.

${ }^{27}$ En el considerando $7^{\circ}$ de la DS, pueden apreciarse los tres elementos mencionados.

${ }^{28}$ Vid. PÉREZ FERNÁNDEZ, J.M. "Directiva de servicios y turismo: el nuevo régimen de acceso y prestación de los servicios turísticos y su contribución al incremento de la calidad turística", cit., págs. 257-318. Así mismo MuÑOz MACHADO, S. "Ilusiones y conflictos derivados de la Directiva de Servicios", en Revista general de Derecho Administrativo, núm. 21, 2009, pág. 3, afirma: "Nunca una directiva comunitaria había tenido tanta ambición regulatoria, ni había afectado de modo tan general a las prácticas administrativas enraizadas en los Estados miembros".
} 


\section{Objetivos, líneas de actuación y contenido de la Directiva}

\subsection{Objetivos}

En línea con el artículo 14.2 del TCE y en aplicación de la Estrategia de Lisboa, la DS persigue alcanzar un auténtico mercado único de servicios en la UE suprimiendo o, cuando menos, minimizando los requisitos administrativos que los ordenamientos de los Estados miembros exigen para la prestación de servicios (considerando $1^{\circ}$ ).

El objetivo básico de la DS, es crear un marco jurídico que garantice plenamente la libertad de establecimiento y de circulación de servicios entre los Estados (considerando $12^{\circ}$ ), eliminando las barreras legales y administrativas que limitaban el ejercicio de esas libertades fundamentales, consagradas en los arts. 49 y 56 del TFUE, manteniendo, al mismo tiempo, un nivel elevado de calidad de los servicios (art. 1.1 DS).

La DS pretende liberalizar la prestación de servicios en la UE, lo que dinamizará el crecimiento económico y la creación de empleo. Para ello, resulta esencial contar con un mercado competitivo de servicios (considerando $4^{\circ}$ ).

Aunque el objetivo principal de la DS es avanzar hacia un auténtico mercado interior de servicios, su aplicación ayudará también a los Estados a modernizar sus administraciones nacionales y sus marcos reguladores haciéndolos más eficientes. Por otra parte, la aplicación de la DS reforzará también los derechos de los usuarios y mejorará la calidad de los servicios en Europa ${ }^{29}$.

\subsection{Lineas de actuación}

Con el fin de lograr el objetivo fundamental de crear un verdadero mercado interior sin fronteras, la DS establece una serie de principios y líneas de actuación, que coinciden, en gran medida, con los propios títulos de los capítulos en que se estructura, y que son los siguientes:

a) Libertad de establecimiento, que obliga a los Estados miembros a una revisión de los regímenes de autorización y a una evaluación de los requisitos exigidos para acceder y ejercer las actividades ${ }^{30}$, y promueve su eliminación o sustitución por otros medios de control menos restrictivos.

\footnotetext{
${ }^{29}$ COMISIÓN “Manual sobre la Transposición de la Directiva de Servicios”, cit., págs. 7 y ss.

${ }^{30} \mathrm{Se}$ establecen varios requisitos evaluables cuyo mantenimiento deberá justificarse tras un análisis de la necesidad y proporcionalidad de los mismos. Asimismo establece unos requisitos expresamente prohibidos como son los relativos a la nacionalidad o residencia, limitaciones al establecimiento en varios Estados miembros o de elección de la forma de establecimiento entre otros.
} 
b) Libre prestación de servicios, que obliga a los Estados a asegurar el acceso a su territorio a los prestadores de otros países, absteniéndose de exigir requisitos específicos o distintos. No obstante este principio tiene excepciones específicas ${ }^{31}$.

c) Simplificación administrativa, que aumente la eficiencia de las Administraciones Públicas y facilite a los prestadores de servicios los trámites y procedimientos que deben seguir ante las mismas.

d) Mejora de la calidad de los servicios, que revierta en mejores prestaciones y atención a los usuarios.

e) Cooperación entre autoridades competentes y asistencia recíproca entre los Estados, para garantizar la adecuada supervisión de los prestadores y sus servicios.

f) Fomento de programas de convergencia que faciliten la armonización en la prestación de servicios y el establecimiento de un prestador en otro Estado.

Estos principios y líneas de actuación inspiran toda la DS y se plasman en una serie de medidas concretas que paso a exponer de forma simplificada.

\subsection{Contenido}

Para entender el contenido y alcance de esta norma, es importante no perder de vista dos hechos, en primer lugar, la DS es la continuación natural del mercado único en el ámbito de los servicios y, en segundo lugar, la DS recoge la jurisprudencia formulada por el TJUE, desde las sentencias de los años 70 Dasonville y Cassis de Dijon ${ }^{32}$, centradas en la eliminación de los obstáculos al comercio intracomunitario ${ }^{33}$. Para cumplir los principios señalados, la DS establece las siguientes medidas ${ }^{34}$.

En materia de simplificación administrativa (capítulo II), la DS apuesta por facilitar el acceso a las actividades de servicios y su ejercicio en el mercado interior y para ello

${ }^{31}$ Como ejemplo podrían citarse determinados servicios de interés económico general, entre ellos los servicios de red (servicios postales y ciertos servicios relacionados con el suministro de gas, agua...).

32 En la Sentencia Cassis de Dijon judgement (Caso 120/78, 20/02/1979), el Tribunal de Justicia de la Comunidad Europea sostuvo que si un bien es producido y comercializado en un estado europeo, los otros estados miembros no tienen derecho a limitar su circulación. Se trata de un principio de confianza mutua, que permitió eliminar de golpe múltiples pequeñas diferencias de regulación que limitaban el progreso del mercado interno. La DS pretende alcanzar un objetivo similar en el sector de servicios y por ello, se inspira en este principio general de confianza mutua.

${ }^{33}$ Vid. MESSERLIN, P.A "The Directive on Services: Rent seekers strike back" en intereconomics, 2005, págs. 121-122.

${ }^{34}$ Véase FERNÁNDEZ RODRÍGUEZ, T.R. "Un nuevo Derecho Administrativo para el mercado interior europeo", en Revista Española de derecho europeo, núm. 22, 2007, pág. 194, en el que señala que "en buena medida, el contenido de la Directiva no es sino una 'codificación' de la jurisprudencia comunitaria. A pesar de que buena parte del contenido de la directiva no sea novedoso en cuanto que no es más que una recopilación, sí representa una novedad de extraordinaria importancia haber convertido esa jurisprudencia en una disposición general y haber montado un sistema específico para asegurar el efectivo cumplimiento de ésta en todo el ámbito de la Unión”. 
considera necesario eliminar las trabas administrativas a través de la simplificación de los procedimientos (art.5). También se apuesta por el establecimiento de ventanillas únicas para la simplificación de los trámites y para que el prestador pueda resolver todas las gestiones a través de un único punto de contacto (art.6). El derecho de información (art.7) y la posibilidad de realizar todos los procedimientos y trámites relativos al acceso y ejercicio de una actividad de servicios a distancia y por vía electrónica $(\operatorname{art} .8)^{35}$, también se orientan a la consecución de este principio.

En materia de libertad de establecimiento y de libre circulación de servicios (capítulos III y IV), la DS pretende la supresión sistemática de las restricciones que limitan o dificultan su ejercicio, por lo que sus previsiones en este punto persiguen suprimir los regímenes de autorización, y los procedimientos y formalidades excesivamente onerosos, que obstaculizan la libertad de establecimiento y la prestación de servicios $^{36}$. La autorización previa obligatoria se limita a los casos en que sea indispensable, señalando los arts. 9 y 16 de la DS que los Estados miembros solo podrán supeditar el acceso a una actividad de servicios y su ejercicio a un régimen de autorización previa, cuando no sea discriminatorio, concurran razones imperiosas de interés general y sea proporcionado. Por su parte, el art.13 regula cómo han de ser los procedimientos de autorización y, su apartado 4, introduce el principio de autorización tácita de las autoridades competentes una vez vencido el plazo determinado ${ }^{37}$.

En materia de calidad de los servicios (capítulo V), la DS establece normas necesarias para lograrla, adoptando medidas que garanticen la máxima información, transparencia y responsabilidad de los prestadores de servicios, de manera que los usuarios y consumidores vean protegidos sus derechos. También se establecen normas relativas a la contratación de seguros, sistemas de certificación y evaluación de las actividades por organismos independientes y etiquetados de calidad, entre otras.

En materia de cooperación administrativa (capítulo VI), la DS proclama la asistencia entre los Estados miembros como un elemento esencial para el correcto funcionamiento del mercado interior de servicios (considerando 105). En este apartado

${ }^{35}$ Vid. JimÉneZ ASENSIO, R. La incorporación de la DS al Derecho interno, cit., pág. 16, destaca que "las disposiciones relativas a la 'simplificación administrativa', son el corolario de un proceso de 'cambio de paradigma' en el modo y manera de comportarse la Administración pública en relación a la libertad de establecimiento y de prestación de servicios".

${ }^{36}$ Véase FERNÁNDEZ RodRíGUEZ, T.R. "Un nuevo Derecho Administrativo para el mercado interior europeo", cit., pág.192, en el que señala que "el marco general que la DS establece para el régimen de autorizaciones supone una verdadera revolución".

${ }^{37}$ Vid. Villarejo Galende, H. y Salvador Armendáriz, M.A. "El complejo proceso de transposición de la Directiva de Servicios”, cit., págs. 93-95. 
se establecen normas dirigidas a los Estados miembros, que pretenden favorecer la efectividad de la DS impulsando la cooperación entre los Estados y entre éstos con la Comisión. Así se establecen obligaciones de asistencia recíproca y de cooperación, que eviten que los prestadores puedan aprovechar situaciones de descoordinación para eludir las supervisiones o normas aplicables.

Finalmente el capítulo VII, establece un programa de convergencia en el que se aprecia que el legislador comunitario es consciente de que el objetivo del mercado interior de los servicios exige una tarea progresiva y que la DS, constituye el primer paso en la consecución de dicho objetivo.

En definitiva, la DS representa un reto, pero también una gran oportunidad para los Estados. Persigue avanzar hacia una Administración más eficiente, liberada de exigir autorizaciones previas y que prescinda de procedimientos y trámites que dificultan el libre acceso y ejercicio de las actividades de servicios. Todo ello, revertirá en una mayor agilidad en los procesos de tramitación y las Administraciones Públicas podrán dedicar recursos a otras actividades necesarias para supervisar, inspeccionar o controlar cómo se ha accedido y cómo se están ejerciendo tales servicios ${ }^{38}$.

\section{Problemas que ha planteado su aplicación}

La UE necesitaba extender el mercado interior único al ámbito de los servicios en el que la unión interior era muy deficiente y se encontraba lejos de hacer realidad el objetivo establecido en el Tratado. Para ello, se requería una estrategia que removiera las barreras nacionales que impedían la plena aplicación de los derechos y libertades de establecimiento y prestación de servicios en todo el territorio de la Unión.

Aunque el objetivo estaba claro, su consecución se vio desde un principio que no iba a resultar pacífica, pues la propuesta de Directiva presentada por la Comisión en 2004, provocó rechazo y su proceso de aprobación se vio interrumpido en varias ocasiones. Las enmiendas introducidas por el Parlamento Europeo transformaron la propuesta inicial de la Directiva Bolkestein creando un texto defectuoso, con numerosas contradicciones y ciertas ambigüedades desde el punto de vista técnico. Finalmente, se aprobó en diciembre de 2006 una versión suavizada del controvertido borrador presentado en enero de 2004 por la Comisión.

\footnotetext{
${ }^{38}$ Vid. JimÉnez ASENSIO, R. La incorporación de la DS al Derecho interno, cit., pág. 94.
} 
En este sentido, un primer problema general que puede apuntarse es la inseguridad jurídica derivada de la defectuosa técnica empleada, que confirió un notable poder al TJUE, que está llamado necesariamente a interpretar la norma ${ }^{39}$.

\subsection{Principio de país de origen}

Aunque hubo varios aspectos controvertidos fue, sin duda, la mención al "país de origen" dentro del título relativo a la libertad de servicios, la verdadera culpable de la gran controversia desatada por la Directiva. De acuerdo con este principio, la legislación aplicable al prestador de servicios que se traslada a otro país europeo, es la de su país de origen y no la del país al que se traslada a prestar sus servicios ${ }^{40}$.

El principio de país de origen deriva de la jurisprudencia del TJUE, que ha influido notablemente en la DS. Para el Tribunal, "no es conforme con la libre prestación de servicios imponer restricciones a un prestador de servicios para salvaguardar intereses generales cuando dichos intereses quedan ya garantizados por las normas a que está sujeto el prestador en el Estado miembro en el que está establecido"41.

Durante la tramitación de la norma, el principio desató muchas críticas. $\mathrm{Su}$ introducción podría causar dumping social y estimular una carrera en la reducción de tutelas sociales, derechos laborales y retributivos ya que, al haber países con regulaciones laborales y sociales con menos cargas para sus operadores, éstos podrían actuar con ventaja en otros países que imponen a sus operadores normas más estrictas.

Para solventar este problema, se suprimió la mención expresa al "principio de país de origen" en el capítulo relativo a la libertad de prestación de servicios, y se incluyeron numerosas excepciones y protecciones para evitar una reducción de derechos laborales y tutelas sociales. Finalmente, en lo relativo a normas sociales y salariales, el principio de país de origen fue sustituido por el principio de país de destino.

Con esas premisas, en abril de 2006, la Comisión elaboró un nuevo texto similar al aprobado por el Parlamento, que sigue la estructura de la primera propuesta aunque de alcance más limitado. Distingue el acceso a los mercados europeos, que debe ser lo más

${ }^{39}$ La adopción de esta directiva ha seguido el procedimiento del art. 251 TCE, por el cual se requiere la aprobación tanto del Parlamento Europeo, como del Consejo Europeo. Con el Tratado de Lisboa, el procedimiento pasó a llamarse proceso legislativo ordinario y se convertirá en el principal proceso legislativo del sistema decisorio europeo. La Directiva fue aprobada con 394 votos favorables; 213 contrarios y 34 abstenciones.

${ }^{40}$ El principio se centra principalmente en aspectos legales relativos a titulaciones, necesidad de autorizaciones particulares, diplomas, regulaciones, etc.

${ }^{41}$ Así se expresa en STJCE de 22/01/2002, as. C-390/99, Canal Satélite Digital, (ap. 38). También

lo había hecho antes la STJCE, de 23/11/1999, ass. C-369/96 y 376/96 Arblade. 
libre y desregulado posible, del ejercicio de las actividades de servicios, que debe seguir las normas del país de destino, para no interferir con los equilibrios de los mercados locales. Los arts. 30 y 31 de la DS recogen el principio de supervisión por parte del Estado miembro en que se preste el servicio, en caso de desplazamiento del prestador.

Sin embargo, la interpretación de estos preceptos y de las normas reguladoras y de las excepciones y sistemas de protección introducidos en la DS, dista mucho de ser clara $^{42}$ y puede plantear problemas interpretativos.

\subsection{El método horizontal que adopta la DS}

El segundo problema que plantea la Directiva, derivado de su alcance horizontal, es delimitar su ámbito material de aplicación. La Directiva se extiende a todos los servicios, salvo los expresamente excluidos o los que están cubiertos por otras disposiciones comunitarias. En este sentido, los arts. 1 y 2.2 de la misma, plantean numerosas salvedades y exclusiones que deben ser oportunamente delimitadas.

Dentro de las actividades a las que no se aplica la DS, se encuentran los servicios no económicos de interés general (art.2.2 a); los que se deben a la existencia de Derecho comunitario derivado de carácter sectorial (apartados b a g del art. 2.2) y los excluidos por razones "políticas", esto es, por voluntad de los Estados miembros de mantenerlos al margen de las obligaciones impuestas por la DS (apartados de h,i,k del art.2.2) ${ }^{43}$. Se trata de una cuestión problemática porque son los Estados los que deben decidirlo.

En definitiva, el ámbito de aplicación de la DS presenta áreas y servicios respecto de los cuales no está clara su aplicación, siendo clave, la precisión con la que los Estados miembros y las autoridades competentes efectúen la transposición. En el caso de España, la transposición y aplicación de la DS resulta, si cabe, más compleja ante la diversidad de fuentes productoras de derecho y la variedad de administraciones que deben aplicarla, lo que exige un plus de coordinación entre las Administraciones implicadas para que la legislación resultante sea coherente y homogénea en todas ellas.

${ }^{42}$ Vid. Villarejo Galende, H. y Salvador Armendáriz, M.A. "El complejo proceso de transposición de la Directiva de Servicios", cit., pág. 87.

${ }^{43}$ Véase Villarejo Galende, H. y SAlVAdor ARMendáRiZ, M.A. "El complejo proceso de transposición de la Directiva de Servicios”, cit., págs. 87 y ss. 
4.3 Eliminación de controles previos como exponente de la liberalización del sector servicios

Otro problema, que plantea la aplicación de la DS, no tanto por la propia Directiva sino por la transposición tan "ambiciosa" que han efectuado tanto el Estado como las CCAA, es la debilitación y pérdida general de controles administrativos previos para la prestación de servicios. Por lo que al objeto de este trabajo respecta, esta cuestión cobra especial importancia en un área muy ligada al interés general, como es el turismo, que puede tener consecuencias negativas para ciudadanos y usuarios.

En efecto, la actividad turística es una actividad económica que afecta directamente a materias medioambientales, patrimoniales, de ordenación del territorio, sociales y de protección de consumidores y usuarios, entre otras, muy vinculadas al interés general, respecto de las que la legislación turística debe buscar un necesario equilibrio.

Aunque la DS tiene un marcado carácter liberalizador y tiende a sustituir las autorizaciones y controles previos por una supervisión posterior, reconoce también la existencia de razones de interés general que justifican una mayor intensidad en la intervención administrativa y el mantenimiento de sistemas de control previo.

En su afán liberalizador, tanto el Estado como las CCAA, han ido más allá de la propia $\mathrm{DS}^{44}$ y a pesar de que ésta permite mantener autorizaciones previas que no sean discriminatorias, sean proporcionadas y estén justificadas en una imperiosa razón de interés general, las CCAA han optado en general por prescindir de esos controles administrativos previos en relación con las actividades turísticas, lo que puede originar problemas importantes para los ciudadanos si, por ejemplo, esa actividad altera valores medioambientales o patrimoniales, o para los propios usuarios, en el caso de actividades de turismo activo que conllevan un riesgo importante en su desarrollo.

En definitiva, la transposición de la DS que se ha hecho, tanto en el Estado como, en materia turística, en las CCAA, ha generalizado la eliminación de controles y autorizaciones administrativos previos que puede plantear problemas de aplicación en relación con actividades cuyo desarrollo está vinculado al interés público.

\footnotetext{
${ }^{44}$ Esta postura es mayoritaria en la doctrina. Así se han pronunciado autores como PAREJO Alfonso, L.J. "La Directiva Bolkestein y la Ley paraguas: ¿legitima el fin cualesquiera medios para la reconversión del Estado 'autoritativo'?”, en Revista española de derecho europeo, núm. 32, 2009, págs. 431-467; CORRAL SASTRE, A. "Libre prestación de servicios y calidad turística. Los efectos de la liberalización del sector", Madrid Tesis Doctoral de 2013, pág. 284; JiMÉNEZ ASENSIO, R. La incorporación de la DS al Derecho interno, cit., págs. 65 y ss.
} 


\section{LA INCORPORACIÓN DE LA DS AL DERECHO INTERNO}

\section{Transposición de la DS en el ámbito estatal}

La DS estableció un plazo máximo de tres años para su incorporación al Derecho interno $^{45}$ que finalizaba el 28 de diciembre de 2009. Puede destacarse desde un primer momento, que el proceso de transposición de la DS y de adaptación normativa en el Estado, en líneas generales, ha sido tardío e incompleto ${ }^{46}$ y que, en algunas cuestiones, ha ido más allá de lo exigido en la propia Directiva.

\subsection{El proceso español de transposición ${ }^{47}$ : Una cuestión compleja}

La estrategia del Gobierno frente a otros países europeos fue optar por un proceso de transposición en dos niveles ${ }^{48}$. Primero, se aprobó una Ley trasversal, la Ley 17/2009, de 23 de noviembre (Ley Paraguas) y, a continuación, una Ley vertical de modificación sectorial, la Ley 25/2009, de 22 de diciembre (Ley Ómnibus) ${ }^{49}$.

La Ley Paraguas fue dictada por el Estado basándose en los títulos competenciales previstos en la Constitución Española, en sus arts. 149.1.1 (condiciones básicas que garanticen la igualdad de todos los españoles en el ejercicio de los derechos y deberes constitucionales); 149.1 .13 (Bases y coordinación de la planificación general de la actividad económica) y 149.1.18 (bases del régimen jurídico de las Administraciones públicas y del régimen estatutario de los funcionarios (...)). Su objeto era lograr una incorporación general de las previsiones recogidas en la DS si bien, en algunos puntos, va más allá de la misma ${ }^{50}$. Por su parte, la Ley Ómnibus es una Ley de naturaleza vertical, que trata de transponer el contenido de la Ley Paraguas a las diversas regulaciones sectoriales de servicios.

${ }^{45}$ Así el art. 44 de la DS señala que "el plazo que los Estados disponen para realizar la transposición, será de tres años" (es decir, hasta el 28 del 12 de 2009).

${ }^{46}$ Vid. JiMÉNEZ ASENSIO, R. La incorporación de la DS al Derecho interno, cit., pág. 7. En este sentido, se ha pronunciado SALVADOR ARMENDÁRIZ Ma A. "Directiva de Servicios y Administración local: cuestiones generales de su transposición en Navarra" en Revista Jurídica de Navarra, núm. 52, 2011, págs. 107-162, señala que "la transposición de la Directiva de Servicios, aún no ha concluido".

${ }^{47}$ Véase Villarejo Galende, H. y SAlvador ARMendÁRiz, M.A. "El complejo proceso de transposición de la Directiva de Servicios”, cit., págs. 103-106.

${ }^{48}$ Vid. RAZQUIN LiZARRAGA, J.A. "El impacto de la Directiva de Servicios en el procedimiento administrativo: Autorización, Declaración responsable y comunicación”, en Revista jurídica de Navarra, núm. 49, 2010, pág. 90 .

${ }^{49}$ Debe señalarse que la primera manifestación de la transposición de la DS en España fue la Ley 11/2007 de 22 de junio, de acceso electrónico de los ciudadanos a los servicios públicos.

${ }^{50}$ Véase JiMÉNEZ ASENSIO, R. La incorporación de la DS al Derecho interno, cit., pág. 81. 
El proceso de transposición de la DS en España, fue complejo por varias razones ${ }^{51}$ :

La primera tiene que ver con la propia naturaleza de la DS y su "originalidad", ya que su verdadero propósito es el de "desregularizar" el sector y para ello, determina límites y condiciones al contenido de las regulaciones nacionales de servicios y establece mecanismos de gestión y organización administrativa extensibles a todas la Administraciones públicas.

La segunda dificultad deriva del carácter trasversal de la norma comunitaria y de la delimitación de su ámbito de aplicación. Determinar con precisión qué servicios engloba la DS y cuáles quedan exceptuados o excluidos, no es una labor sencilla.

El tercer motivo es la implicación en este proceso de multitud de autoridades competentes $^{52}$ ya que en España, además del Estado, son competentes las CCAA, las EELL y algunas entidades privadas cuando ejerzan funciones públicas de autorización.

Con todo, esta dificultad no debe constituir un freno para la incorporación de la norma comunitaria como ha recordado el TJUE, indicando que no pueden los Estados miembros escudarse en su estructura federal para justificar su posible incumplimiento ${ }^{53}$.

En resumen, la complejidad de este proceso de transposición radicó en el amplio alcance del proceso desregulador perseguido, en la indeterminación previa de las materias que iban a quedar potencialmente afectadas y en la necesaria implicación y coordinación de todos los niveles de poder territorial. Todo ello, llevó a que la Administración General del Estado liderase el proceso de transposición, destacando el papel encomendado al Ministerio de Economía y Hacienda. Se trata por tanto de un proceso largo, complejo y, en un Estado de estructura compuesta como el nuestro, plural y desigual en sus manifestaciones, por el número de niveles de gobierno afectados y las distintas percepciones políticas que éstos pueden tener ${ }^{54}$.

${ }^{51}$ Vid. Villarejo Galende, H. y Salvador ArmendÁriz, M.A. "El complejo proceso de transposición de la Directiva de Servicios", cit., págs. 103 y ss.

${ }^{52}$ El art. 4.9 DS define "autoridad competente", entendiendo por tal "cualquier organismo o entidad en un Estado, que lleve a cabo el control o la regulación de las actividades de servicios y, concretamente, las autoridades administrativas, incluidos los tribunales que actúen como tales, los colegios profesionales y las asociaciones u organismos profesionales que, en el marco de su autonomía jurídica, regulan de forma colectiva el acceso a las actividades de servicios o su ejercicio". La DS es consciente de que sus obligaciones no deben perjudicar al reparto de competencias en la organización de los Estados, por ello, el considerando 60 señala "en particular las disposiciones referentes a los regímenes de autorización y al ámbito territorial de una autorización, no deben interferir en el reparto de competencias regionales o locales en los Estados, incluidos los gobiernos autónomos regionales y locales".

${ }^{53}$ Vid. STJCE (13/06/2002), Comisión/España. En este sentido, véase MuÑOz MACHADO, S. "La transposición de la Directiva al ordenamiento español", en Revista asociación para el Progreso de la Dirección, núm. 231, 2008, págs. 26-29.

${ }^{54}$ Véase JiMÉNEZ ASENSIO, R. La incorporación de la DS al Derecho interno, cit., pág. 114. 


\subsection{La Ley 17/2009, transposición de carácter horizontal}

La Ley 17/2009, de 23 de noviembre, sobre el libre acceso a las actividades de servicios y su ejercicio (LLAASE), supone una modalidad específica de transposición, no seguida por otros países europeos, y consiste en la elaboración de una Ley horizontal $^{55}$. El Gobierno apostó por este método de incorporación de la DS basándose en diversas razones recogidas en la Memoria de la Ley. Entre otras, establecer criterios de actuación comunes para todas las Administraciones públicas; prever reglas de coordinación; dar "visibilidad" y "efectividad" a las disposiciones de la DS y facilitar la “inaplicación" general de normas incompatibles con el contenido de la ley horizontal. ${ }^{56}$

Esta Ley establece las disposiciones generales necesarias para facilitar la libertad de establecimiento de los prestadores y la libre circulación de servicios, simplificando los procedimientos y fomentando un nivel elevado de calidad de los servicios, así como limitando la introducción de restricciones injustificadas o desproporcionadas (art.1).

La Ley constituye una transposición formal que se limita, en gran medida, a reiterar el contenido de la DS y tiene carácter de incorporación parcial $^{57}$, abierta y flexible, pero con un enfoque más amplio que el de la propia $\mathrm{DS}^{58}$. Establece los principios generales que deben regir la regulación de las actividades de servicios, por lo que adopta también un carácter horizontal o transversal ${ }^{59}$. Desde la perspectiva competencial, es una ley de carácter básico (disposición adicional $1^{\circ}$ ), a respetar por las $\mathrm{CCAA}^{60}$.

La LLAASE sirve exclusivamente para establecer unas "bases" que sólo obligarán en lo que excede de los contenidos propios de la DS a los legisladores autonómicos, pero no al legislador sectorial estatal, que podría apartarse de lo previsto en esa "ley horizontal" pues no es, ni formal ni materialmente, de rango superior a la ley sectorial que pueda aprobar en cada caso las Cortes Generales.

${ }^{55}$ Vid. JIMÉNEZ ASENSIO, R. La incorporación de la DS al Derecho interno, cit., pág. 111.

${ }^{56}$ Idea tomada de JiMÉnEZ ASENSIO, R. La incorporación de la DS al Derecho interno, cit., pág. 73.

${ }^{57}$ El dictamen del Consejo de Estado al anteproyecto de Ley sobre libre acceso y ejercicio de las actividades de servicios (Dictamen 99/2009 de 18 de marzo) señala que este tipo de incorporación de la DS a derecho interno representa una 'transposición parcial' a través de una ley abierta y flexible que se limita en muchas casos a reproducir los preceptos de la DS, y que, por tanto, es un proceso de transposición que deberá continuar con la adecuación del marco normativo sectorial en todos los niveles de gobierno territorial. Así lo subraya la DA $2^{\mathrm{a}}$ LLAASE, cuando afirma "mediante esta ley se incorpora parcialmente al Derecho interno español la Directiva 2006/123/CE (...)".

${ }^{58}$ El Pleno del Consejo de Estado en dictamen 99/2009, cit., artículo $1^{\text {o }}$, persigue también otro objetivo como es el de evitar la introducción de restricciones al funcionamiento de los mercados de servicios que no resulten justificadas o proporcionadas.

${ }^{59}$ Vid. PAREJO ALFONSO "La Directiva Bolkestein y la Ley paraguas: ¿legitima el fin cualesquiera medios para la reconversión del Estado 'autoritativo'?”, cit., págs. 431-467.

${ }^{60}$ Así lo destaca el Pleno del Consejo de Estado en dictamen 99/2009, cit., antecedente segundo, apartado cuarto. 
Por consiguiente, la aprobación de una "ley horizontal" de estas características parece que cobra su único sentido en cuanto que pretende establecer unas medidas adicionales de obligado cumplimiento, dada su condición de "básicas", para el legislador autonómico. En lo demás, el legislador podría haber operado directamente modificando las leyes sectoriales correspondientes como han hecho otros países (Francia, Alemania o Reino Unido).

La justificación del recurso a una "ley horizontal", puede encontrarse en el uso que el legislador estatal "básico" hace de los títulos "horizontales" o "transversales" por excelencia, como son los recogidos en los arts. 149.1.1 y 149.1.13 CE, puesto que la invocación del art.149.1.18 CE puede estar justificada en casos muy singulares ${ }^{61}$.

En suma, la estructura territorial del Estado español y, particularmente, el interés de sujetar el modo y manera como la DS era incorporada en el ordenamiento jurídico español de carácter sectorial, parece estar en el fondo de esa decisión por transponer a través de una "ley paraguas" la citada Directiva ${ }^{62}$. De hecho, en esta formulación subyace una suerte de "desconfianza" en cómo puedan llevar a cabo la transposición de ese derecho comunitario los poderes autonómicos y locales ${ }^{63}$.

En opinión de R. JIMÉNEZ ASENSIO, “el retraso en la tramitación de la Ley, ha terminado por echar por tierra el pretendido 'efecto pedagógico' que quería tener, con el fin de que las CCAA y las EELL siguieran los pasos del gobierno central. En realidad lo que se ha conseguido es el efecto contrario, es decir, se han producido una serie de 'retrasos en cadena', ya que la mayoría de los gobiernos autonómicos y locales han esperado a que se aprobara la "Ley paraguas"64. Por tanto, la opción escogida por el Gobierno español de transponer la Directiva a través de una ley horizontal, ha retrasado enormemente el proceso de adaptación de la normativa autonómica y local ${ }^{65 "}$.

Por último, cabe destacar que esta Ley recoge las figuras de declaración responsable y la comunicación previa, sin embargo, solamente define la declaración responsable. Ambas figuras serán introducidas, a través de la Ley 25/2009, en el artículo 71 bis de la Ley 30/1992, de 26 de noviembre, de régimen jurídico de las Administraciones públicas y del procedimiento administrativo común (en adelante, LRJPAC).

\footnotetext{
${ }^{61}$ Véase JimÉnEZ ASENSIO, R. La incorporación de la DS al Derecho interno, cit., pág. 112.

${ }^{62}$ Vid. JiMÉNEZ ASENSIO, R. La incorporación de la DS al Derecho interno, cit., pág.113.

${ }^{63}$ Véase JiMÉNEZ ASENSIO, R. La incorporación de la DS al Derecho interno, cit., pág.121.

${ }^{64}$ Valoración que realiza JIMÉNEZ ASENSIO, R. La incorporación de la DS (...), cit., pág. 110.

${ }^{65}$ Vid. JIMÉNEZ ASENSIO, R. La incorporación de la DS (...), cit., pág. 121.
} 
Así, según la LRJPAC, la declaración responsable es "el documento suscrito por un interesado en el que manifiesta, bajo su responsabilidad, que cumple con los requisitos establecidos en la normativa vigente para acceder al reconocimiento de un derecho o facultad o para su ejercicio, que dispone de la documentación que así lo acredita y que se compromete a mantener su cumplimiento durante el periodo de tiempo inherente a dicho reconocimiento o ejercicio". Por su parte, la comunicación previa es "el documento mediante el que los interesados ponen en conocimiento de la Administración Pública competente sus datos identificativos y demás requisitos exigibles para el ejercicio de un derecho o el inicio de una actividad, de acuerdo con lo establecido en el artículo 70.1". A pesar de que la Ley define ambas figuras, la doctrina ha destacado las deficiencias de la configuración legal de estas dos figuras, que conduce a confusión y solapamiento de ambas técnicas ${ }^{66}$.

\subsection{La Ley 25/2009, transposición de carácter vertical}

Un mes más tarde de la publicación de la Ley 17/2009, se aprobó la Ley 25/2009, de modificación de diversas leyes para su adaptación a la LLAASE, denominada "Ley ómnibus" $" 67$ (en adelante LML), que fue publicada en el BOE el 23 de diciembre de 2009. Esta nueva Ley procedió a una transposición sectorial de la DS, modificando diversas leyes reguladoras de la prestación de servicios con arreglo al contenido de la "Ley paraguas" ${ }^{\prime 68}$. De la Memoria del Proyecto de Ley se puede extraer la idea de que se trata de una disposición modificativa múltiple, que representa un segundo nivel en el proceso de transposición de la DS.

La finalidad de la citada norma es doble. Por un lado, adaptar la normativa estatal de rango legal a lo dispuesto en la Ley 17/2009 y, por otro, extender los principios de buena regulación a sectores no afectados por la DS para dinamizarlos y mejorar la competitividad. Para ello sigue un enfoque ambicioso, que permitirá contribuir de

\footnotetext{
${ }^{66}$ Vid. PÉREZ Fernández J.M. "Directiva de servicios y turismo: el nuevo régimen de acceso y prestación de los servicios turísticos y su contribución al incremento de la calidad turística”, cit., pág. 299. Así mismo, López Menudo, F. "La transposición de la Directiva de Servicios y la modificación de la Ley 30/1992: el régimen de la declaración responsable y de la comunicación previa”, en Revista Española de la Función Consultiva, núm. 14, 2010, pág. 124, afirma que afirma que "basta la mera lectura del precepto para apreciar que cualquiera de las dos figuras tiene la virtualidad de permitir el ejercicio de una actividad".

${ }^{67}$ Denominación que proviene de la vieja caracterización de las "leyes de acompañamiento a los Presupuestos Generales del Estado".

${ }^{68}$ Según el preámbulo de la LML, modifica entre otras, la Ley 7/1985, de 2 de abril, Reguladora de las Bases del Régimen Local; la Ley 2/1974, de 13 de febrero, sobre Colegios Profesionales; la Ley 31/1995, de 8 de noviembre, de Prevención de Riesgos Laborales; la Ley 32/2003, General de Telecomunicaciones, etc.
} 
manera notable a la mejora del entorno regulatorio del sector de servicios y a la supresión efectiva de requisitos o trabas no justificadas o desproporcionados ${ }^{69}$.

Sin embargo, esta ley planteó diversas controversias. Una de ellas, tenía que ver con el propio título de la Ley. En efecto, era muy discutible, tanto desde el punto de vista formal como material, que una ley ordinaria como la LML sea "adaptación" de otra ley ordinaria como la LLAASE, al menos en lo que representa la relación entre dos leyes estatales que forman parte del mismo sistema y subsistema normativo. Este hecho llama la atención ya que entre ambas leyes no hay ninguna relación de jerarquía, ni tampoco una relación competencial ni de procedimiento. Ambas se aprueban por mayoría simple en las Cortes Generales y no se puede defender la primacía de ninguna de ellas. Es más, entre ambos tipos de leyes opera el principio cronológico, en virtud del cual la ley posterior deroga la ley anterior.

El problema se sitúa en que una vez dictada la "ley horizontal", y dado que sus pretensiones eran llevar a cabo una transposición ambiciosa de la propia DS, el legislador español se ha inclinado por una adaptación en la que la legislación sectorial no se adapta a la DS sino a la LLAASE ${ }^{70}$.

Como resultado de la transposición de la DS en el Derecho estatal, se han producido una serie de cambios muy relevantes, en materia de Derecho administrativo, que han afectado fundamentalmente a la LRJPAC y a la LBRL en gran parte, debidos a la Ley 25/2009, de 22 de diciembre. En el primero de los casos, esos cambios han afectado al reconocimiento legal de los principios de proporcionalidad y favor libertatis, a la regulación de la declaración responsable y de la comunicación previa y a la reforma del silencio administrativo. Por lo que a la reforma de la LBRL se refiere, los cambios más importantes han afectado a la regulación del régimen de autorizaciones y licencias $^{71}$.

Por último, cabe destacar que las CCAA y las EELL, independientemente de que existiera o no una ley horizontal estatal, estaban obligadas a adaptar su legislación, reglamentos y ordenanzas a la DS. Algunas CCAA habían aprobado ya determinadas disposiciones normativas que, con mayor o menor acierto, invocaban la DS. Sin

\footnotetext{
${ }^{69}$ Véase RAZQUin LiZARRAGA, J.A. "El impacto de la Directiva de Servicios en el procedimiento administrativo: Autorización, Declaración responsable y comunicación”, cit., págs. 85-136.

${ }^{70}$ Vid. JiMÉNEZ ASENSIO, R. La incorporación de la DS al Derecho interno, cit., págs. 174 y 175.

${ }^{71}$ Véase SAlvador ARMENDÁRIz, $\mathrm{M}^{\mathrm{a}}$ A. "Directiva de Servicios y Administración local: cuestiones generales de su transposición en Navarra", cit., págs. 107-162.

${ }^{72}$ Vid. RAZQUin LiZARraGA, J.A. "El impacto de la Directiva de Servicios en el procedimiento administrativo: Autorización, Declaración responsable y comunicación”, cit., pág. 123.
} 
embargo, la gran mayoría presentaban un escenario de absoluto incumplimiento de las obligaciones de adaptar sus disposiciones normativas a las previsiones de la $\mathrm{DS}^{72}$.

\section{Transposición de la DS en la Comunidad Foral}

Las CCAA en el ámbito de sus competencias, deben aplicar la DS con pleno respeto a lo dispuesto en ella y también en la Ley 17/2009, que constituye legislación básica dictada al amparo del art.149.1.1 ${ }^{\mathrm{a}}, 13^{\mathrm{a}}$ y $18^{\mathrm{a}}$ de la $\mathrm{CE}$ y a las medidas horizontales sobre procedimiento administrativo de la Ley 25/2009, dictadas al amparo del artículo 149.1.18 a de la CE, con el carácter de legislación básica ${ }^{72}$.

Para transponer la DS, el legislador foral optó por un modelo similar al del Estado, realizando la transposición en dos niveles. Primero, aprobó la Ley Foral 15/2009, de 19 de diciembre, de medidas de simplificación administrativa para la puesta en marcha de actividades empresariales o profesionales, con un alcance horizontal y, en una segunda fase, la Ley Foral 6/2010, de 6 de abril, de modificación de diversas leyes forales para su adaptación a la DS, con un carácter sectorial. Se añade a ellas la Ley Foral 7/2010, de 6 de abril, de modificación de la Ley Foral 6/1990, de 2 de julio de la Administración Local de Navarra ${ }^{73}$, que se tramitó de manera separada en razón de su carácter de ley de mayoría absoluta. Por tanto, la transposición de la DS se ha llevado a cabo en Navarra a través de tres normas legales, aunque sólo las dos últimas explicitan dicha finalidad y su adaptación a la Ley 17/2009.

\subsection{La Ley Foral 15/2009, transposición de carácter trasversal}

La Ley Foral 15/2009, contiene una serie de medidas trasversales dirigidas fundamentalmente a la Administración de la Comunidad Foral, con la finalidad de proceder a su modernización a través de la eliminación o simplificación de trámites y cargas administrativas que no sean imprescindibles ${ }^{74}$.

Aunque nada se indica en ella en relación con la DS, de su contenido se puede concluir que tiene una relación estrecha con los presupuestos de la norma comunitaria, ya que, entre otras, recoge un conjunto de medidas administrativas para facilitar la puesta en marcha de actividades empresariales o profesionales (art. 1.1); establece los objetivos de eliminar cargas administrativas innecesarias, crear nuevos mecanismos de

\footnotetext{
${ }^{73}$ Vid. RAZQUin LiZARRAGA, J.A. "El impacto de la Directiva de Servicios en el procedimiento administrativo: Autorización, Declaración responsable y comunicación”, cit., pág. 124.

${ }^{74}$ Vid. SAlVADOR ARMENDÁRIZ, Ma A. "Directiva de Servicios y Administración local: cuestiones generales de su transposición en Navarra”, cit., págs. 148-162.
} 
relación con la Administración Foral, impulsar la administración electrónica y simplificar los procedimientos (art. 2) y contempla figuras para agilizar la tramitación administrativa, como el estudio de cargas administrativas, la declaración responsable, la comunicación previa o las licencias condicionadas (art. 3).

\subsection{La Ley Foral 6/2010, transposición de carácter sectorial}

Frente a la transposición horizontal llevada a cabo por la Ley Foral 15/2009, la incorporación de la DS a la Comunidad Foral de modo sectorial se materializa con la Ley Foral 6/2010, de 6 de abril, de modificación de diversas leyes forales para su adaptación a la Directiva 2006/123/CE de Servicios. Esta Ley Foral tiene como objetivo completar el proceso de transposición de la DS al ordenamiento jurídico de Navarra, mediante la modificación de seis leyes forales sectoriales, relativas a colegios profesionales, juego, salud, comercio no sedentario, comercio y turismo, reguladoras de la prestación de diversos servicios en la Comunidad Foral.

Por lo que al objetivo de este trabajo respecta, una de las leyes modificadas es la Ley Foral 7/2003, de 14 de febrero, reguladora del Turismo en Navarra. Principalmente, la modificación tiene por objeto la ordenación de la actividad turística contenida en su título III. Consecuencia de esta modificación es la aprobación un año más tarde del Decreto Foral 10/2011, de 14 de febrero, de modificación de siete decretos forales reguladores de diversos ámbitos del turismo, que habían sido elaborados con anterioridad a la transposición de la DS al Derecho interno.

Por último, ha de mencionarse la modificación de la Ley Foral de la Administración Local operada por el art. 2 de la Ley Foral 7/2010, de 6 de abril, exigencia derivada, no sólo de la obligación de la trasposición de la DS al ámbito local, sino también de la necesidad de trasladar a Navarra, las novedades incorporadas al art. 84 de la LBRL, que se tramitó de manera separada por ser Ley de mayoría absoluta ${ }^{75}$.

\section{La transposición de la DS como un proceso dinámico que debe profundizarse y aplicarse en el tiempo}

La aplicación al Derecho interno de la DS no se puede dar por finalizada con la aprobación de las normas de transposición que tanto el Estado, como las CCAA y la Comunidad Foral han aprobado hasta la fecha. Se trata de un proceso abierto de

\footnotetext{
${ }^{75}$ Vid. RAZQUIN LiZARRAGA, J.A. "El impacto de la Directiva de Servicios en el procedimiento administrativo: Autorización, Declaración responsable y comunicación”, cit., pág. 124.
} 
actualización y profundización permanente que no ha concluido, porque la propia norma comunitaria contempla que la incorporación del modelo de reformas que ella impulsa va a requerir un proceso dinámico ${ }^{76}$ y porque la transposición tiene que llegar a todos los sectores y niveles de las Administraciones públicas, especialmente, a las locales e implica la adaptación no sólo legislativa y reglamentaria, sino también de técnicas, trámites y procedimientos administrativos muy diversos.

El avance e intensificación de ese proceso se irá consolidando conforme se asuma "el cambio de paradigma" que representa pasar de una Administración basada en una intervención previa, a otra cuyas pautas de funcionamiento se centran en una intervención "ex post" iniciado de adaptación de la normativa interna a sus previsiones, sino que la puesta en marcha de este nuevo modelo de intervención administrativa sobre el mercado interior de servicios se proyecta en todo lo relativo a la simplificación administrativa, lo que implicará revisar en profundidad muchos de los trámites y procedimientos existentes en la Administraciones ${ }^{78}$. Asimismo, este proceso debe estar abierto a los criterios que marque la jurisprudencia del TJUE que irá modulando en el tiempo su aplicación.

\section{IV.- MARCO JURÍDICO REGULADOR DEL TURISMO EN NAVARRA}

\section{La situación anterior a la entrada en vigor de la Directiva}

La Constitución Española de 1978 prevé que las CCAA podrán asumir competencias en "promoción y ordenación del turismo en su ámbito territorial" (art.148.1.18 a). Al amparo de esta previsión, la totalidad de las CCAA han incorporado a sus Estatutos de Autonomía la competencia sobre turismo con carácter exclusivo.

En coherencia con la exclusividad autonómica, el artículo 149 CE no contiene ninguna reserva competencial directa en favor del Estado sobre turismo, por lo que no existe ninguna regulación general del turismo a nivel nacional. Se trata de un sector con claro protagonismo autonómico. Sin embargo, el Tribunal Constitucional ha señalado que el artículo 149.1 CE, atribuye al Estado la titularidad de diversas competencias que, en mayor o menor medida, pueden incidir sobre la competencia exclusiva antes señalada ${ }^{79}$.

${ }^{76}$ Así se señala en el artículo 39.4 de la Directiva 2006/123/CE, de Servicios.

${ }^{77}$ Véase JIMÉNEZ ASENSIO, R. La incorporación de la DS al Derecho interno, cit., pag.9.

${ }^{78}$ Véase JiMÉNEZ ASENSIO, R. La incorporación de la DS al Derecho interno, cit., pág. 11.

${ }^{79}$ PÉREZ FERnÁndez J.M. "Directiva de servicios y turismo (...)", cit., pág. 260 que a su vez se remite a la STC $125 / 1984$, de 20 de diciembre, Fundamento Jurídico $1^{\text {o }}$. 
El Amejoramiento del Fuero en su artículo 44 recoge, como competencia exclusiva de Navarra, la promoción y ordenación del turismo. Por Real Decreto 1191/1985, se traspasaron a Navarra las funciones y servicios del Estado en materia de turismo ${ }^{80}$.

Siendo la ordenación del turismo competencia exclusiva de Navarra, sorprende la escasa regulación existente en los años 80 y 90 y la ausencia de una norma de rango legal hasta la elaboración de la Ley Foral 14/1997, de 17 de noviembre, de disciplina turística, que se aprobó para asegurar la reserva de ley en materia sancionadora. Su exposición de motivos, indicaba que en los últimos años Navarra había experimentado un notable desarrollo como destino turístico y para consolidar dicho desarrollo se apostó por unos servicios e instalaciones turísticos de calidad. Para ello, resultaba necesario dotar a la Administración Foral de unos mecanismos de inspección y sanción que permitieran asegurar el cumplimiento de la normativa turística.

Sin embargo, esta Ley Foral se limitó a regular, por un lado, la Inspección de Turismo como función especializada, dotándola de los instrumentos jurídicos necesarios para cumplir sus funciones $y$, por otro, a tipificar las conductas sancionables, fijando las sanciones y regulando el procedimiento para su imposición. Fuera de ello, no contenía una regulación completa de un sector en auge que requería una regulación integral ${ }^{81}$.

A falta de una norma con rango de ley, el sector se regulaba mediante Decretos Forales referidos a cuestiones organizativas ${ }^{82} \mathrm{y}$ a otros aspectos de la actividad

La calificación de la competencia autonómica en materia de turismo como «exclusiva» está lejos de ser clara y pacífica, teniendo cuando menos un «carácter marcadamente equívoco» como ha reseñado en varias ocasiones el propio Tribunal Constitucional (SSTC 37/1981, de 16 de noviembre, FJ $1^{\circ}$, y 5/1982, de 8 de febrero, $\mathrm{FJ} 1^{\circ}$ ). Así el Alto Tribunal, afirma que si bien «las normas constitucionales y estatutarias relativas a la distribución de competencias clasifican la realidad social en materias para ordenar aquella distribución», no es menos cierto que «los conceptos de materias allí recogidos poseen, en ocasiones, un inevitable grado de indeterminación y es frecuente que una materia, en concreto el turismo, tenga dimensiones clasificables dentro de otro concepto material y encajables en otro título competencial» (STC $125 / 1984, \mathrm{FJ} 1^{\circ}$ ).

En relación con la virtualidad del título ex artículo $149.1 .13^{\mathrm{a}} \mathrm{CE}$ en el ámbito del turismo, véanse la STC 75/1989, de 24 de abril, FJ $3^{\circ}$ y $4^{\circ}$, en la que el Tribunal considera que la previsión de subvenciones y ayudas en materia de turismo y la regulación genérica de sus condiciones entra en la competencia estatal de «ordenación general de la economía»; y la ya citada STC 125/1984, FJ 1º en la que rechaza la virtualidad del título estatal de ordenación general de la economía en relación con la posibilidad de clasificar los establecimientos hoteleros (lo que sería aplicable a todo tipo de establecimientos turísticos).

${ }^{80}$ Vid. RAZQUIN LIZARRAGA, M M ${ }^{\mathrm{a}}$. "La ordenación jurídica del turismo en navarra", en Revista jurídica de Navarra, núm. 35, 2003, págs. 39-72.

${ }^{81}$ Idea que aparece en la exposición de motivos de la Ley Foral 14/1997, de 17 de noviembre.

${ }^{82}$ Ejemplo de ello, el Decreto Foral 246/1985, de 27 de diciembre, sobre Consejo de Turismo de Navarra y el Decreto Foral 342/1999, de 17 de noviembre, por el que se crea la Comisión de coordinación de la Promoción del Sector Turístico. 
turística $^{83}$. Por tanto, la ordenación jurídica del turismo en Navarra se limitó hasta el año 2003, a una regulación reglamentaria con la salvedad de la Ley Foral 14/1997 ${ }^{84}$.

Será en el año 2003 cuando Navarra se dote de una Ley Foral, la 7/2003, de 14 de febrero de Turismo, que regule esta materia de forma global y completa. Se trata de una ley integradora, clara y bien estructurada, que establece una serie de objetivos, fines y principios que sintonizan, en gran medida, con los de la futura DS, como la apuesta por la calidad, la protección medioambiental, la preocupación por los derechos de los usuarios y la coordinación y colaboración entre las Administraciones públicas implicadas. Además, la Ley delimita las competencias entre la Administración Foral y las Entidades locales, regula diversos aspectos de la organización administrativa del turismo y recoge las especialidades de algunos sectores turísticos como los de alojamiento, restauración, mediación y otras actividades y profesiones turísticas.

Tras la entrada en vigor de la Ley Foral de Turismo, se dictaron varios Decretos Forales, que desarrollaron diversos aspectos sectoriales de la actividad turística, entre los que destacan el DF 502/2003, de 25 de agosto, sobre el Registro de Turismo de Navarra; el DF 146/2005, de 26 de diciembre, de Alojamientos Hoteleros; el DF 140/2005, de 5 de diciembre, de Albergues; el DF 24/2009, de 30 de marzo, de Campamentos y el DF 288/2004, de 23 de agosto, de Turismo Activo y cultural.

\section{Regulación del turismo en Navarra tras la transposición de la DS}

Tras la aprobación de la DS en 2006, Navarra esperó a que el Estado procediera a su transposición a nivel nacional, que se produjo con las Leyes 17/2009 (LLAASE) y 25/2009 (LML). Mediante Ley Foral 15/2009, de medidas de simplificación administrativa para la puesta en marcha de actividades empresariales o profesionales, la Comunidad Foral se dotó de una Ley de carácter horizontal para aplicar la LLAASE. Sin embargo, habrá que esperar hasta la Ley Foral 6/2010, de 6 de abril, para que se aborde la modificación de la legislación turística de Navarra para su adaptación a la DS.

En efecto, el artículo 6 de esa Ley Foral modifica diversos preceptos de la Ley Foral 7/2003 de Turismo, entre los que destacan sus artículos 13, 14 y 26. En esencia, el cambio consiste en la sustitución del control administrativo previo de las actividades

\footnotetext{
${ }^{83}$ Son ejemplo, el Decreto Foral 141/1988, de 4 de marzo sobre agencias de viaje; el Decreto Foral 48/1994, de 21 de febrero, sobre ordenación de los Establecimientos Hoteleros; el Decreto Foral 69/1999, de 1 de mayo, sobre Albergues Turísticos o el Decreto Foral 143/1999, de 28 de junio, sobre Casas Rurales. 72.

${ }^{84}$ Vid. RAZQUIN LIZARRAGA, M Ma " "La ordenación jurídica del turismo en navarra”, cit., págs. 39-
} 
turísticas, con un régimen de autorización basado en una decisión administrativa de inscripción con silencio positivo; por un sistema de declaración responsable, cuya presentación bastará para considerar cumplido el deber de inscripción en el Registro de Turismo de Navarra, que habilita al operador turístico a ejercer su actividad desde su presentación, pasando el control administrativo a ser "ex post".

Posteriormente, mediante Decreto Foral 10/2011, de 14 de febrero, se modifican siete decretos forales, aprobados con anterioridad a la transposición de la DS al Derecho interno, reguladores del Registro de Turismo de Navarra (DF 500/2003), de Establecimientos Hoteleros (DF 146/2005), de Albergues Turísticos (DF 140/2005), de Casas Rurales (DF 243/1999), de Campamentos de Turismo (DF 24/2009), de Turismo Activo y Cultural (DF 288/2004) y de Agencias de Viajes (DF 141/1988). En esencia, la modificación introducida consiste también en trasladar a estos sectores el nuevo régimen de libre acceso y ejercicio de la activad turística, mediante la presentación de la declaración responsable.

En definitiva, más allá del cambio de modelo señalado para el inicio de la actividad y de alguna modificación puntual del régimen disciplinario, la regulación del turismo en Navarra tras la transposición de la directiva ha permanecido prácticamente inalterada.

Frente a la amplitud de objetivos y líneas de actuación marcadas por la DS, la reforma operada en el sector turístico en Navarra, se ha limitado a la modificación del régimen de acceso y ejercicio de la actividad turística, partiendo de los artículos 11 y 13 de la Ley Foral 15/2009, relativos a la declaración responsable, sin abordar otro tipo de medidas que la DS planteaba, en relación con la simplificación administrativa, el apoyo a los operadores turísticos, el derecho de información, la utilización de procedimientos telemáticos, la implantación de mecanismos eficaces de control posterior, la apuesta por la calidad, el turismo sostenible, el enfoque hacia el usuario de los servicios turísticos o la cooperación y coordinación entre las Administraciones públicas.

En lo que respecta al inicio de la actividad turística y su inscripción en el Registro de Turismo, la reforma se limita a introducir en los artículos 13 y 14 de la Ley la declaración responsable como modo general de inicio de la actividad, pero no regula en esa sede de manera clara y ordenada cuestiones importantes que pueden plantearse sobre esa declaración, sus posibles deficiencias, la inscripción registral y el proceso de comprobación administrativa posterior. Por otra parte, aunque la DS permite mantener un régimen de autorización previa en determinados supuestos, la LFT no lo recoge, quedando todas las actividades sujetas al régimen de declaración responsable. 
Siendo tan relevante el cambio de modelo operado para el inicio de actividades turísticas, basado en la presentación de una declaración responsable, por el que se desplaza al operador la responsabilidad por su declaración, debieran contemplarse también en la actual legislación medidas dirigidas a la formación e información de los operadores turísticos por parte de la administración o de mecanismos de apoyo, como el informe previo, que favorezcan al máximo la corrección de dicha declaración y eviten los problemas que de su incorrección pueden derivar una vez iniciada la actividad.

También es notorio el cambio de modelo operado por la DS en materia de inspección y control de la actividad, en la medida en que el peso se desplaza del control previo anterior a la comprobación posterior de la corrección de la declaración y de la actividad a los requisitos exigidos. Sin embargo, la LFT no ha introducido cambio alguno respecto al funcionamiento y modo de actuación de la inspección turística que debe, en el nuevo escenario, reorientar su función y ejercerla con la máxima agilidad.

En este mismo ámbito de la disciplina turística, tampoco la reforma de la LFT introducida en 2010 ha modificado en lo sustancial el régimen de infracciones y sanciones, más allá de la introducción de algunas referencias puntuales a las que tienen que ver con la no presentación o presentación defectuosa de la declaración responsable. En este sentido, la puesta al día de la clasificación de los diferentes tipos de infracciones $\mathrm{y}$, especialmente, el reforzamiento del régimen sancionador, tanto principal como accesorio, es una necesidad dado que se ha quedado un tanto desfasado.

En materia de calidad, aunque la LFT la recoge en su artículo 4.c) como un principio básico de actuación, no ha incorporado mecanismos concretos que puedan reforzarla, como el establecimiento de un procedimiento de presentación y tramitación ante la administración turística de quejas y reclamaciones por los usuarios, más allá de reconocer este derecho en su artículo 31.f, o el establecimiento de planes periódicos de inspección que verifiquen la situación de los establecimientos o actividades registradas.

A pesar de la importancia que la DS les da, la LFT tampoco recoge medidas concretas tendentes a reformar la propia organización y funcionamiento de la administración turística en línea con la simplificación administrativa y la apuesta por la administración electrónica que propugna, ni con el establecimiento de mecanismos concretos de cooperación y coordinación que permitan la máxima interconexión de bases y registros entre la administración turística y el resto de administraciones que pueden disponer de información relevante para el ejercicio de la actividad turística. 
Asimismo, entiendo que la DS exige también incorporar a la LFT una serie de actividades y servicios turísticos que están surgiendo con fuerza en los últimos años y que sin embargo la actual Ley Foral no regula o lo hace de manera muy escueta. En esta misma línea, la LFT debiera también contemplar y regular otro tipo de actividades que sin ser propiamente turísticas, por su importancia, inciden notablemente en el sector turístico.

Profundizaré más en estas materias en el apartado $\mathrm{V}$ de este trabajo, a propósito de la propuesta de reforma del marco jurídico regulador del turismo en Navarra, pasando a analizar a continuación el cambio de modelo producido en Navarra en el ejercicio de la actividad turística y la regulación de la declaración responsable, especialmente, en la LRJPAC y en la legislación turística de Navarra, en la medida en que ambas cuestiones constituyen la piedra angular de la reforma de la LFT operada en 2010.

\section{El cambio de modelo en el ejercicio de actividades turísticas: de la autorización} administrativa previa a la declaración responsable

La Directiva de Servicios considera que una de las principales dificultades a que se enfrentan los prestadores de servicios, reside en la complejidad, la extensión y la inseguridad jurídica de los procedimientos administrativos. Por este motivo, un objetivo primordial de la misma es la simplificación administrativa (artículo 5 DS), a través de la cual se eliminan trámites innecesarios o excesivamente complejos y costosos, y se evita la duplicación de operaciones, las formalidades burocráticas en la presentación de documentos y los plazos indeterminados o excesivamente largos ${ }^{85}$.

Con este objetivo y siguiendo el modelo por el que, en general, han optado las CCAA, la Ley Foral 6/2010 introdujo en la Ley Foral 7/2003 de Turismo, la figura de la declaración responsable como único documento necesario para iniciar la actividad turística. Ello ha provocado un cambio en el modo de actuar de la Administración Foral, que ha pasado de un control "ex ante" a través de la autorización de la actividad turística, a un control posterior a través de la figura de declaración responsable.

El principal efecto de suprimir con carácter general el control administrativo previo, es desplazar el centro de gravedad situándolo en los prestadores de servicios turísticos. La doctrina habla de "cambio de paradigma", ya que asistimos al nacimiento

${ }^{85}$ Bermejo LATRE, J.L. y ESCARTín EsCudé, V. "El impacto de la reforma de servicios en el sector del turismo", en Revista Aragonesa de Administración Pública, pág. 496. 
de un nuevo modelo de intervención, en la medida en que se postula la sustitución del tradicional control previo, vía autorización, por un control posterior. Este nuevo modelo transforma el rol de la Administración, al poner el acento sobre el control y la verificación posterior, pasando la inspección a desempeñar una labor de supervisión de la actividad privada y del propio particular, que asume un especial protagonismo y responsabilidad. Frente al régimen de autorización previa anterior, la Administración asume ahora una posición y menos intervencionista y de control "ex post".

Por concretar qué ha supuesto en la práctica el cambio de modelo, señalaré que antes de la reforma de 2010, el prestador de servicios turísticos presentaba una solicitud al Departamento de Turismo manifestando su voluntad de iniciar la actividad, junto con los documentos exigidos. La sección de registro procedía a darle entrada y la trasladaba al servicio de inspección, que comprobaba lo indicado en la solicitud. Se señalaba una fecha para la inspección y una vez realizada, los inspectores redactaban su informe que, prácticamente en todos los casos, señalaba diversas deficiencias que debía subsanar el solicitante. El Departamento otorgaba un plazo de subsanación de deficiencias y, una vez transcurrido, la inspección volvía a intervenir para comprobar que los defectos habían desaparecido. En caso de subsanación, el servicio de inspección emitía informe definitivo y el Director General firmaba la resolución, normalmente en el plazo aproximado de un mes desde el informe definitivo, autorizando el ejercicio de la actividad y su inscripción. Desde la presentación de su solicitud, el operador turístico debía esperar un mínimo de cuatro meses para iniciar la actividad, siendo frecuente que ese plazo pudiera alargarse en caso de que la inspección detectase deficiencias que era preciso subsanar.

Actualmente el procedimiento es más sencillo y ágil para el operador turístico. El nuevo artículo 14 de la LFT indica que la inscripción en el Registro de Turismo de Navarra, que es requisito esencial para ejercer la actividad, se realizará con la sola presentación por los interesados de una declaración responsable, en la que manifiestan el cumplimiento de los requisitos y el compromiso de su mantenimiento durante el tiempo de vigencia de la actividad. Ahora, el prestador de servicios turísticos presenta la declaración responsable junto con la documentación correspondiente $y$, automáticamente, puede empezar a ejercer su actividad, asignándosele un código que le permitirá publicitarse a través de cualquier medio de difusión. Paralelamente, se traslada a inspección la documentación indicada para que efectúe el control de la actividad y emita el correspondiente informe. Si el informe es favorable, el Director General de 
Turismo firma la Resolución de inscripción y la empresa se incorpora al Registro de Turismo de Navarra. Desde 2015, el control de la inspección se realiza en algunos casos, como apartamentos turísticos y pensiones, desde la sede de la inspección.

En definitiva el cambio sustancial radica, además de en una mayor agilidad del procedimiento para el operador, en el hecho de que el prestador de servicios turísticos, desde el mismo instante en que presenta su declaración responsable, puede ejercer la actividad de manera legal, incluso durante ese plazo de comprobación administrativa.

La desaparición de la autorización turística no implica la de otros controles "ex ante" por razones medioambientales, urbanísticas o de tutela del patrimonio cultural, y que la intervención autonómica convive con el mantenimiento por los Entes Locales de licencias de urbanismo o actividades clasificadas.

Por último, debe subrayarse que, aunque la Ley 17/2009 y la Ley Foral 15/2009 recogían junto a la figura de la declaración responsable la comunicación previa, Navarra no la ha contemplado esta última en la legislación turística.

\section{La declaración responsable en el ordenamiento jurídico estatal y foral}

\subsection{La figura de la declaración responsable}

La figura de la declaración responsable no es extraña a nuestro ordenamiento jurídico, pues en ámbitos como la contratación pública ya era habitual su utilización como medida de simplificación administrativa, que permite a un licitador sustituir la presentación de determinados documentos ante la administración por una declaración responsable manifestando que los cumple. Sirva como ejemplo el artículo 18.3 de la Ley Foral 6/2006, de 9 de junio, de Contratos Públicos, que permite a los licitadores sustituir la presentación de diversos documentos acreditativos de la no concurrencia de determinadas prohibiciones para contratar, por una declaración responsable dirigida a la entidad contratante en la que manifiesten que no concurren en ellos esas prohibiciones. Una previsión similar se recogía en el artículo 62.1 de la Ley 30/2007, de 30 de octubre, de Contratos del Sector Público.

En todo caso lo que sí es cierto es que la entrada en vigor de la DS y su transposición al derecho nacional ha multiplicado las referencias a esta figura como modo de inicio de actividades económicas en diversos ámbitos, como el del turismo. Fue la Ley 17/2009, la que en la transposición "horizontal" de la DS al ordenamiento jurídico español introdujo, en su artículo 3.9, una breve definición de la declaración responsable como "el documento suscrito por la persona titular de una actividad 
empresarial o profesional en la que declara, bajo su responsabilidad, que cumple con los requisitos establecidos en la normativa vigente, que dispone de la documentación que así lo acredita y que se compromete a mantener su cumplimiento durante la vigencia de la actividad".

Habrá que esperar, sin embargo, a la Ley 25/2009, cuyo artículo 2 incorpora el nuevo artículo 71 bis a la Ley 30/1992, LRJPAC, para encontrar una configuración legal más completa de esta figura.

\subsection{Su regulación en el nuevo artículo 71 bis de la Ley 30/1992}

La Ley 25/2009, a través de su artículo 2, introduce en la LRJPAC, el nuevo artículo 71 bis que regula la declaración responsable y la comunicación previa y lo hace, según la disposición final primera de la ley, bajo el título competencial del artículo 149.1.18 de la CE con el carácter de legislación básica sobre el régimen jurídico de las Administraciones Públicas. Ha de destacarse, por tanto, que ese contenido es obligatorio y debe recogerse en la legislación turística foral, por lo que es importante delimitar la configuración y el régimen jurídico de esta figura en la LRJPAC.

$\mathrm{Su}$ apartado 1 define la declaración responsable en términos similares a la Ley $17 / 2009$, si bien señala que se presentará por el titular de la actividad y no por el interesado. El apartado 1 final resalta que los requisitos de la declaración responsable deberán estar recogidos de manera expresa, clara y precisa en la correspondiente declaración $\mathrm{y}$, el apartado 5, dispone que las Administraciones tendrán permanentemente publicados y actualizados modelos de declaración responsable, que se facilitarán de forma clara e inequívoca y, en todo caso, se podrán presentar a distancia y por vía electrónica.

El efecto inmediato de la presentación de la declaración responsable, previsto en el apartado 3 de este artículo, es el reconocimiento con carácter general del ejercicio de un derecho o del inicio de una actividad, sin perjuicio de las facultades de control e inspección de la Administración.

El apartado 4, por su parte, regula las consecuencias de la presentación defectuosa o incorrecta de la declaración responsable, señalando que "la inexactitud, falsedad $u$ omisión, de carácter esencial, en cualquier dato, manifestación o documento que se acompañe o incorpore a una declaración responsable (...), o la no presentación ante la administración competente de la declaración responsable (...), determinará la imposibilidad de continuar con el ejercicio del derecho o actividad afectada desde el 
momento en que se tenga constancia de tales hechos, sin perjuicio de las responsabilidades penales, civiles o administrativas a que haya lugar. Asimismo, la resolución de la Administración Pública que declare tales circunstancias podrá determinar la obligación del interesado de restituir la situación jurídica al momento previo al reconocimiento o al ejercicio del derecho o al inicio de la actividad correspondiente, así como la imposibilidad de instar un nuevo procedimiento con el mismo objeto durante un periodo de tiempo determinado (...)”.

Siguiendo este apartado, pueden establecerse dos supuestos en relación con las deficiencias de una declaración responsable, según sean o no de carácter esencial, al que habría que añadir un tercer supuesto, en el caso de ejercer la actividad sin haber presentado la declaración. Las deficiencias esenciales o la no presentación de la declaración conllevan consecuencias contundentes para el operador ya que determinan la imposibilidad de continuar con el ejercicio de la actividad, pudiendo la Administración determinar la obligación del interesado de restituir la situación al momento previo al inicio de la actividad y la imposibilidad de instar un nuevo procedimiento con el mismo objeto durante un periodo de tiempo determinado.

A este respecto, autores como Mariola Rodríguez Font destacan que la Sentencia núm. 1141/2013 de 10 octubre de 2013 del Tribunal Superior de Justicia de Andalucía, reconoce el derecho de subsanación de una declaración responsable que contenga omisiones o errores esenciales, lo que deja sin sentido la propia distinción que la ley implícitamente instaura entre lo que son datos u omisiones esenciales y los que no lo son, anudando las mismas consecuencias jurídicas a unas u otras ${ }^{86}$.

A la vista del artículo 71 bis de la LRJPAC, pueden formularse las siguientes consideraciones $^{87}$ sobre el régimen jurídico de la declaración responsable que, por su carácter de básico, deben ser tenidas en cuenta por el legislador foral:

$1^{\text {a }}$.- La declaración responsable es un acto privado de los interesados, no de la Administración.

$2^{\mathrm{a}}$.- Con su declaración el particular asume la responsabilidad de la veracidad de su contenido y de la adecuación de la actividad a los requisitos establecidos.

86 Véase RODRÍGUEZ FONT, M. "La contribución inicial de la jurisdicción contenciosoadministrativa a la construcción del régimen de control a posteriori (comunicación previa y declaración responsable)", en Revista Andaluza de Administración Pública, núm. 90, 2014, págs. 187-226.

${ }^{87}$ Vid. PÉREZ FERNÁNDEZ, J.M. "Directiva de servicios y turismo: el nuevo régimen de acceso y prestación de los servicios turísticos y su contribución al incremento de la calidad turística", cit., pág. 312. 
$3^{\text {a }}$ - La declaración responsable permite el ejercicio inmediato de la actividad desde su presentación, sin que suponga iniciar ningún proceso de autorización administrativa.

$4^{\mathrm{a}}$.- Lo que sí puede desencadenar su presentación es el inicio de la actividad inspectora y comprobadora "ex post" por parte de Administración, con su correspondiente procedimiento.

5a.- El inicio de una actividad sin la previa presentación de una declaración responsable o su presentación con inexactitudes, falsedades u omisiones de carácter esencial, debe llevar aparejada la aplicación de un régimen sancionador riguroso.

$6^{\circ}$.- La Administración ha de poner los medios para que la declaración responsable recoja de manera expresa y clara el cumplimiento de los requisitos que ha de contener, debiendo facilitar a los interesados formularios claros y actualizados.

En todo caso y como señalan algunos autores ${ }^{88}$, aunque la mayoría de las CCAA han optado en el ámbito del turismo por la incorporación de la figura de la declaración responsable, su aplicación práctica no está resultando todo lo clara, ordenada y coherente que sería deseable, en primer lugar, por la confusión con la figura de la comunicación previa y, en segundo lugar, por su concurrencia con otras técnicas de control como licencias municipales o de actividades clasificadas, cuya articulación no está bien resuelta, amén de que en la práctica el cambio de mentalidad en la actuación de la Administración turística lleva su tiempo.

\subsection{La declaración responsable en la LF 15/2009, de 9 de diciembre.}

La Ley Foral 15/2009, de medidas de simplificación administrativa para la puesta en marcha de actividades empresariales o profesionales, ley de transposición horizontal de la DS a la Comunidad Foral, define en su preámbulo la declaración responsable y la comunicación previa, en línea con la DS y la Ley 17/2009, “como instrumentos que permiten iniciar la actividad empresarial o profesional correspondiente en mucho menor plazo, cambiándose el control previo de la Administración por el control posterior, siempre con la garantía de la responsabilidad del promotor de la iniciativa y la presentación de todos los documentos requeridos".

El artículo 11 de la LF 15/2009, en su apartado 1, define la declaración responsable en términos similares a los contemplados en la legislación estatal si bien, su apartado 2 ,

\footnotetext{
${ }^{88}$ Vid. PÉREZ FERNÁNDEZ, J.M. "Directiva de servicios y turismo: el nuevo régimen de acceso y prestación de los servicios turísticos y su contribución al incremento de la calidad turística", cit., pág. 304.
} 
señala que uno de los aspectos que debe contener es la declaración de no haber formulado previamente otra declaración responsable que haya resultado nula. Por otra parte, este apartado 2 señala que la presentación de toda la documentación que se requiera conllevará, automáticamente, la concesión de la licencia de actividad, que estará condicionada a la efectiva verificación del ajuste a la normativa vigente. Es decir, solo la presentación de una declaración responsable correctamente formulada y de la documentación requerida conlleva automáticamente la concesión de la licencia de actividad que, por otra parte, queda condicionada a la efectiva verificación del ajuste a la normativa vigente. En este punto señalaré que esta previsión, en mi opinión, va más allá de la regulación que se recoge en el artículo 71 bis 3, de la LRJPAC.

Es sin embargo el artículo 13 de la LF 15/2009, el que regula más ampliamente la presentación y control por la Administración de la declaración responsable. Por un lado, su apartado 1 dispone que en el plazo de un mes desde su entrada en vigor, la Administración de la Comunidad Foral deberá tener diseñados los modelos de declaración responsable tanto en soporte digital para que pueda ser cumplimentada través del portal web, como en papel, que deberán ser puestos a disposición de las personas interesadas recogiendo de manera expresa y clara los requisitos exigidos (apartado 2). El apartado 3, por su parte, resalta que la presentación de la declaración responsable faculta a la Administración para comprobar, en cualquier momento, la veracidad de los documentos, datos y cumplimiento de los requisitos exigidos, para lo cual impulsará la función inspectora de los órganos competentes. El apartado 4 señala, en términos categóricos, que la falsedad o inexactitud en cualquier dato, manifestación o documento de carácter esencial que se acompañe o incorpore a una declaración responsable implicará la nulidad de lo actuado, impidiendo desde el momento en que se conozca el ejercicio de la actividad afectada, sin perjuicio de las responsabilidades penales, civiles o administrativas a que hubiera lugar. Por último, el apartado 5 dispone que la resolución de la Administración que declare las circunstancias aludidas en el apartado anterior, podrá determinar la obligación del interesado de restituir la situación jurídica al estado que tenía en el momento previo al ejercicio de la actividad, así como la imposibilidad de instar un nuevo procedimiento con el mismo objeto durante un periodo de tiempo determinado en función de las normas que resulten de aplicación.

Puede concluirse que la LF 15/2009 regula con bastante detalle la configuración de la declaración responsable en Navarra y su presentación y control por la Administración $\mathrm{y}$, salvo aspectos puntuales, coincide a grandes rasgos con la regulación estatal y, 
especialmente, con la prevista en el artículo 71 bis de la LRJPAC, a pesar de que su nueva redacción se introdujo por la Ley 25/2009, que fue aprobada unos días después que la Ley Foral 15/2009.

\subsection{La declaración responsable en la legislación turística de Navarra.}

La transposición de la declaración responsable a la legislación de turismo en Navarra se lleva a cabo por la Ley Foral 6/2010, de 6 de abril, de modificación de diversas leyes forales para su adaptación a la DS, entre las que se encuentra la LFT modificada por el artículo 5 de aquella Ley Foral. En lo que nos afecta, la modificación incide fundamentalmente en los artículos 13 y 14 de la LFT y se limita a introducir la figura de la declaración responsable como elemento clave para el inicio de la actividad turística, la inscripción en el Registro de Turismo y el ejercicio de las potestades administrativas de control.

El artículo 13.1 de la LFT proclama que el ejercicio de la actividad turística es libre señalando su párrafo 2 que, sin perjuicio de ello, las empresas y establecimientos turísticos, con carácter previo al inicio de su actividad, deberán estar inscritos en el Registro de Turismo de Navarra, requisito que se cumple, según el apartado 4 de dicho artículo, mediante la presentación de la declaración responsable prevista en el artículo 14 de la LFT. Concluye este párrafo señalando que la publicidad o la efectiva prestación de servicios turísticos sujetos a inscripción sin haber presentado esa declaración, será considerada actividad clandestina, tipificada como infracción grave (artículo 54.1 a).

El artículo 14 de la LFT, por su parte, referido al Registro de Turismo de Navarra reitera, con carácter general, la obligatoriedad de la inscripción para el ejercicio de actividades turísticas (apartado 2), que se practicará a través de la presentación por los interesados de una declaración responsable (apartado 3), que bastará para considerar cumplido el deber de inscripción (apartado 4). El apartado 5, por su parte, señala que el Departamento competente en materia de turismo realizará la inscripción en el Registro conforme al contenido de la declaración responsable, sin perjuicio de las potestades administrativas de control y la adopción, en su caso, de las medidas cautelares o sancionadoras que pudieran corresponder.

Según el artículo 14.3 LFT, los interesados que presenten la declaración responsable "manifestarán el cumplimiento de los requisitos establecidos en la normativa vigente relativos al servicio o establecimiento y su clasificación y el 
compromiso de su mantenimiento durante el tiempo de vigencia de la actividad, así como la disposición, en su caso, de la documentación acreditativa que corresponda".

La regulación de la declaración responsable en la LFT se completa con el régimen sancionador, que considera infracción leve presentar la declaración responsable careciendo de documentos que al efecto sean exigibles por la normativa turística o con inexactitud de los datos (artículo 53, apartados o y p); infracción grave la realización clandestina de una actividad turística, esto es, sin presentación previa de la declaración responsable, o el incumplimiento o alteración de los requisitos de inscripción (artículo 54.1, apartados a y b); e infracción muy grave la alteración dolosa de los aspectos sustantivos para la inscripción (artículo 55.1, apartado c). Estas infracciones conllevan el correspondiente régimen sancionador previsto en los artículos 57 a 61 de la LFT.

En relación con este régimen sancionador ligado a la no presentación o presentación deficiente de la declaración responsable considero que, en general, no es excesivamente riguroso. Considerar como falta leve, que tan solo lleva aparejada como sanción el apercibimiento o la multa de hasta 1.200 euros, presentar la declaración responsable careciendo de los documentos exigibles por la normativa turística o presentarla con inexactitudes sin mayor concreción, parece poco exigente (artículos 53 o y p en relación con el 58.1 de la LFT). Otro tanto puede señalarse de considerar la actividad clandestina, es decir la realizada sin declaración ni inscripción, como infracción tan solo grave (artículo 54.1 a) LFT) al igual que el incumplimiento o alteración de los requisitos de la inscripción (artículo 54.1 b) de la LFT).

Contrastando la regulación de la declaración responsable en la LFT, con la contenida en los artículos 11 y 13 de la LF 15/2009 y, especialmente, con la regulación básica del artículo 71 bis de la LRJPAC, se aprecian algunas carencias.

En primer lugar, por lo que se refiere a las obligaciones de la Administración, la LFT no recoge de manera expresa y clara la obligación de tener permanentemente publicados y actualizados modelos de declaración responsable, que se facilitarán de forma clara e inequívoca y que, en todo caso, se podrán presentar a distancia y por vía telemática. Ni de que estos modelos deberán recoger de manera expresa, clara e inequívoca los requisitos que la declaración debe contener (artículos 71 bis 5 y 1 de la LRJPAC).

En segundo lugar, por lo que se refiere a las deficiencias de la declaración responsable y sus consecuencias, la LFT no define claramente cuando una inexactitud, falsedad u omisión en los datos, manifestaciones o documentos que se acompañen a una 
declaración responsable tienen carácter esencial o no, ni determina de manera categórica las consecuencias de esas deficiencias, como lo hacen tanto la LF 15/2009 (artículo 13.4) como la LRJPAC (artículo 71 bis 4).

En tercer lugar, por lo que respecta a la resolución de la Administración que declare esas circunstancias, nada dice la LFT al respecto frente a lo dispuesto en el artículo 71 bis 4, segundo párrafo, de la LRJPAC, según el cual esa resolución podrá determinar la obligación del interesado de restituir la situación jurídica al momento previo al reconocimiento o ejercicio del derecho o al inicio de la actividad, así como la imposibilidad de instar un nuevo procedimiento con el mismo objeto durante un periodo de tiempo determinado.

En definitiva, no se puede negar que la declaración responsable en la LFT es un elemento central que sirve, desde el punto de vista del operador, para iniciar la actividad turística y, desde el punto de vista de la Administración, para inscribir de oficio la actividad en el Registro de Turismo de Navarra y, en su caso, para el ejercicio de las facultades de comprobación e inspección que pueden dar lugar a la aplicación de un régimen sancionador. Sin embargo, la regulación de una cuestión tan importante como esta debiera ser más amplia y contemplar de forma clara y homogénea, en sede de los actuales artículos 13 y 14 de la LFT, los aspectos señalados anteriormente. Asimismo, esta regulación debiera contener la articulación, ahora dispersa, de una secuencia clara y coherente entre la presentación de la declaración responsable, la inscripción en el registro y el ejercicio de la actividad inspectora posterior por parte de la Administración, así como la situación en que queda el operador turístico o terceros interesados en relación con una actividad ya iniciada, que está siendo objeto de control cuando la inspección detecta incumplimientos de los requisitos para ejercerla. También sería deseable reforzar, como he señalado, el régimen sancionador previsto para el caso de declaración responsable presentada con inexactitudes, errores y defectos, para que actúe como elemento preventivo de conductas indeseadas.

Por ello sería deseable que todas estas cuestiones se regulasen en la legislación turística de una manera conjunta, clara y coherente, teniendo en cuenta lo dispuesto en los artículos 11 y 13 de la LF 15/2009 y, especialmente, lo señalado en el nuevo artículo 71 bis de la LRJPAC, que por su carácter de básico obliga al legislador foral. 


\section{Reflexiones sobre la transposición de la DS en Navarra en el ámbito del turismo}

Como reflexión final sobre la transposición de la Directiva Bolkestein a Navarra, sorprende que una norma comunitaria tan relevante y de tanto calado jurídico, que plantea tantas líneas de actuación, haya dado lugar a una modificación tan puntual en la Ley Foral de Turismo y en toda su regulación reglamentaria, basando prácticamente todo ese cambio en la introducción de la declaración responsable como requisito para ejercer la actividad turística. El cambio, como ha quedado reflejado en el apartado anterior, es importante y podríamos decir que, en ese punto, la normativa foral ha ido, incluso, más allá que la propia Directiva en su afán liberalizador del sector pero, en mi opinión, ha sido un cambio incompleto e insuficiente, de alcance muy limitado.

Teniendo la Comunidad Foral una oportunidad única para realizar una reforma profunda del régimen jurídico regulador de este sector tan importante para Navarra, siguiendo las pautas de la Directiva, ha centrado su transposición en una única línea de actuación dejando de lado otras también relevantes, como la apuesta por la calidad y el turismo sostenible, la modernización de la administración turística, la información y formación de los operadores turísticos, la transformación del modelo de control, el reforzar la colaboración y la coordinación entre las Administraciones públicas y los operadores turísticos o la orientación hacia los intereses de los usuarios.

Por otra parte, la reforma introducida tanto por la Ley Foral 6/2010 como por el DF 10/2011, no aborda una regulación sobre las modificaciones que supone en la práctica el propio cambio de modelo y de enfoque, que permite ejercer una actividad turística con la sola presentación por el operador de una declaración responsable. En efecto, con la nueva regulación la responsabilidad de la actividad turística, pasa de la administración a los prestadores de servicios. Sin embargo, poco dice la nueva regulación de los cambios organizativos y de funcionamiento que necesariamente conlleva este cambio de modelo en la propia Administración turística o en sus servicios de inspección, ni se articula de manera clara la declaración responsable con los elementos que inciden en la adecuada realización de la actividad turística. Tampoco se ha aprovechado la reforma para poner al día el régimen de infracciones y sanciones que el propio cambio de modelo exigía.

Por último, más allá de la transposición de la DS aunque también vinculada a sus objetivos de modernizar y poner al día la regulación del sector servicios, se podría haber aprovechado la ocasión para regular las nuevas realidades del sector turístico que están surgiendo con fuerza en los últimos años y para dar respuesta a los problemas planteados en el sector, a la luz de la experiencia que ha supuesto la aplicación de la 
LFT en estos últimos 12 años, en un sector tan dinámico y en constante evolución, que está sufriendo cambios importantes en estos años.

Todas estas razones justifican plenamente, en mi opinión, la necesidad de reformar en profundidad la Ley Foral del Turismo de 2003, para su plena adaptación a la DS, en los términos que planteo en el apartado siguiente.

\section{NECESIDAD DE ACTUALIZAR EL MARCO JURÍDICO REGULADOR DEL TURISMO EN NAVARRA PARA SU PLENA ADAPTACIÓN A LA DS: LÍNEAS DE ACTUACIÓN PARA SU REFORMA.}

\section{El turismo como una realidad poliédrica cuya regulación debe ir más allá de su} consideración de mera actividad económica

Ya he señalado anteriormente que, dentro del ámbito de los servicios, las actividades turísticas además de su importancia como motor de desarrollo económico, están muy ligadas a una serie de valores medioambientales, patrimoniales, culturales y sociales, que deben ser tenidos en cuenta en su regulación.

Tras la etapa desarrollista en esta materia que tuvo lugar en España en la década de los 60 y 70 del siglo anterior, la CE de 1978 es sensible a esos valores y reconoce como principios rectores de la política social y económica la protección del medio ambiente (art. 45), la conservación del patrimonio histórico y cultural (art. 46), la promoción de una adecuada utilización del ocio (art. 43.3) y la defensa de los derechos e intereses de los consumidores y usuarios (art. 51), principios, por otra parte, íntimamente vinculados con el desarrollo del turismo sostenible que deben inspirar el derecho del turismo.

La DS, aunque quiere promover los principios de libre establecimiento y libre circulación de servicios y, con ellos, la competitividad y la creación de un verdadero mercado interior de servicios removiendo las barreras nacionales que lo obstaculizan, también aboga por la defensa de los valores de la calidad, del medioambiente, del patrimonio cultural, del desarrollo sostenible y de la protección de los consumidores y usuarios, entre otros.

En consecuencia, Navarra como titular exclusivo de la competencia en materia turística deberá abordar la regulación del turismo procurando un equilibrio entre el desarrollo económico que esta actividad supone y que, indudablemente, está ligado a la plena implantación de los principios de libertad de establecimiento y de libre circulación de servicios proclamados por la DS, y el desarrollo sostenible, viable, 
respetuoso con el medio ambiente y los valores patrimoniales, culturales y sociales del territorio en el que se desarrolla, con una clara orientación hacia el usuario.

Si se rompe este equilibrio, el turismo se vuelve insostenible, de ahí la importancia de que el nuevo marco regulador sea sensible a ello, máxime en una comunidad como Navarra, en la que los valores medioambientales, culturales y sociales están especialmente arraigados en la ciudadanía e íntimamente unidos al territorio.

La LFT ya proclamaba en 2003 estos principios en sus artículos 3 y 4 sintonizando bien con la DS, por lo que partimos de una base sólida que habrá que actualizar y reforzar, a la vista de la realidad cada vez más evidente de que el turismo se está convirtiendo en un fenómeno de masas, en el que es preciso buscar un equilibrio entre todos los intereses en juego preservando, en todo caso, de forma decidida los recursos turísticos y medioambientales.

\section{2.- La regulación detallada del inicio de la actividad turística y de la inscripción en el Registro de Turismo de Navarra}

Con el cambio de modelo para el acceso al ejercicio de las actividades turísticas, que pone el acento en la declaración responsable del prestador del servicio, sería deseable desde el punto de vista de la seguridad jurídica, que la nueva ley incluyera desde el principio una regulación clara y coherente de los elementos esenciales que inciden en el ejercicio de la actividad turística, por su importancia para todos las partes implicadas: el prestador, el usuario y la administración. En este sentido, el art. 13.1 de la DS señala que "los procedimientos y trámites de autorización deberán ser claros, darse a conocer con antelación y ser adecuados para garantizar a los solicitantes que su solicitud reciba un trato objetivo e imparcial".

Frente al modelo de autorización previa anterior, que conllevaba todo un procedimiento administrativo que, aunque prolijo, ofrecía también sus garantías, considero que el actual modelo de inicio de la actividad turística es mucho más ágil para el operador turístico, pero por ello requiere también de un mayor rigor y claridad que evite que, una vez iniciada la actividad, su no adecuación a los requisitos exigidos, genere mayores problemas al prestador, a los usuarios y a la propia Administración.

La actual regulación sobre el régimen jurídico de las actividades turísticas (art. 13 LFT) y el Registro de Turismo de Navarra (art. 14 LFT) señala, en esencia, que el ejercicio de la actividad turística es libre; que con carácter previo a su inicio las empresas turísticas deberán estar inscritas en el Registro de Turismo de Navarra; que la 
inscripción se practicará a través de la presentación por los interesados de una declaración responsable; que la presentación de esta declaración bastará para considerar cumplido el requisito de inscripción en el Registro; que el Departamento competente realizará la inscripción conforme al contenido de la declaración responsable y que, todo ello, se efectuará sin perjuicio de las potestades administrativas de control y de la adopción, en su caso, de las medidas cautelares o sancionadoras que procedan.

Entiendo, sin embargo, que esta regulación es incompleta. Una materia tan importante como es el inicio de la actividad turística, bajo el nuevo modelo implantado, debiera ofrecer una regulación más completa y clara de los aspectos básicos que inciden en ella, por lo que sería deseable completar los arts. 13 y 14 de la LFT, empezando por adecuar la figura de la declaración responsable y su régimen jurídico a lo dispuesto en el artículo 71 de la LRJPAC, estableciendo de manera clara las obligaciones de la Administración Turística y determinando qué son deficiencias esenciales o no, así como sus consecuencias para la actividad turística y el operador. Sería también deseable establecer una secuencia clara entre los elementos que inciden en el inicio de la actividad, como la propia declaración responsable, la inscripción registral y el ejercicio de las facultades comprobadoras de la Administración, así como contemplar posibles medidas de asesoramiento al operador previas a la presentación de su declaración.

La LFT señala que desde la presentación de la declaración se entiende cumplida la obligación de inscripción para iniciar la actividad. Sin embargo en la práctica, esta inscripción no se produce con la sola presentación del citado documento, sino tras un proceso administrativo interno en el que interviene la inspección y diversos órganos de la Administración Turística, concluyendo con la resolución del Director General resolviendo sobre la inscripción. Es decir, existe en la práctica un periodo de tiempo en el que el prestador ejerce la actividad sin que se haya producido la inscripción, lo cual plantea una contradicción con el artículo 13.2 de la LFT, que dispone "que las empresas y establecimientos turísticos, con carácter previo a la iniciación de su actividad, deberán estar inscritos en el Registro de Turismo de Navarra".

La ambiciosa transposición de la DS efectuada en Navarra en este punto plantea un inicio de actividad con la sola presentación de la declaración responsable, que conlleva el cumplimiento automático del requisito de inscripción en el Registro. Sin embargo, la actual regulación no recoge debidamente ordenados todos los elementos que concurren en el proceso y que sería deseable contemplar de una manera coherente. En definitiva, regular en detalle los aspectos esenciales que afectan al inicio de la actividad turística, 
supone una garantía para todos los implicados y un mayor grado de seguridad jurídica, si tenemos en cuenta que la actividad se inicia con la presentación de la declaración responsable y los defectos y errores que puedan producirse en este procedimiento, van a tener una mayor trascendencia porque la actividad ya está en marcha ${ }^{89}$.

\section{La oportunidad de recuperar la autorización previa en el caso de actividades}

\section{turísticas que afecten notoriamente al interés general}

La DS pretende lograr un verdadero mercado interior de los servicios y, para ello, aborda una profunda liberalización del sector, mediante la eliminación de trabas y barreras que faciliten la libertad de establecimiento y la libre circulación de servicios entre los Estados miembros. Por ello, uno de sus objetivos fundamentales es la sustitución de controles y autorizaciones administrativas previas, por comunicaciones y declaraciones responsables, así como por controles posteriores.

Sin embargo la propia DS contempla el mantenimiento de sistemas de autorización previa, tanto respecto a la libertad de establecimiento (artículo 9) como a la libre circulación de servicios (artículo 16), siempre que sean proporcionados, no discriminatorios y estén justificados por razones imperiosas de interés general, concepto que se vincula de modo abierto a diversos ámbitos como el orden público, la seguridad y la salud pública, la protección de los consumidores y usuarios, la protección de los trabajadores, el bienestar animal, la protección del medio ambiente, del entorno humano o la conservación del patrimonio histórico-artístico (considerando 40 DS).

La transposición estatal de la DS, mediante la Ley 17/2009, ha ido más allá que la Directiva en este punto, acotando el carácter abierto de las materias que aquella vincula al interés general, a las relacionadas con el orden público, la seguridad pública, la salud pública y la protección del medio ambiente (arts. 5, 7 y 12 Ley 17/2009).

Por su parte, la transposición efectuada en la Comunidad Foral mediante la Ley Foral 6/2010, cuyo artículo 6 modifica la Ley Foral 7/2003 de Turismo, se limita en esencia a modificar los requisitos para el ejercicio de actividades turísticas, sustituyendo el régimen de autorización previa anterior, por el de inscripción automática en el Registro de Turismo mediante presentación de una declaración responsable por el interesado. Esta transposición se completa en el ámbito reglamentario mediante el DF 10/2011, de modificación de diversos reglamentos en materia de turismo, que extiende

\footnotetext{
${ }^{89}$ Véase a este respecto el procedimiento detallado de inicio de actividad y registro turístico que se incluye en los arts. 20-25 del Anteproyecto de Ley de Turismo del País Vasco, aprobado en 2015.
} 
el nuevo modelo, a cada uno de los sectores de actividad turística regulados reglamentariamente: establecimientos hoteleros, albergues, casas rurales, campamentos, turismo activo y agencias de viaje.

En su afán por eliminar controles previos, la normativa foral de transposición ha "olvidado" la posibilidad de establecerlos, siempre que se cumplan los requisitos que la DS establece y las actividades turísticas afecten o incidan de manera notoria en materias vinculadas al interés general.

Por ello, considero necesario retomar este tipo de autorizaciones previas en el caso de actividades turísticas con afecciones importantes en materias de interés general como el medio ambiente y seguridad de los usuarios, siempre que los controles posteriores puedan resultar tardíos o insuficientes. En este sentido, actividades de turismo activo y de aventura tan de moda en Navarra, vinculadas a la naturaleza, con afecciones medioambientales importantes y que conllevan un riesgo inherente para los usuarios, serían el ejemplo más claro de actividad turística que debiera estar sujeta a autorización administrativa previa como recoge, por ejemplo, la Ley de Turismo de Aragón ${ }^{90}$.

\section{La implantación de mecanismos eficaces de supervisión posterior}

A raíz de la reforma que provocó en Navarra la DS, sustitución del control previo por el control "ex post", se produjo un cambio muy importante en el papel de la Administración y, en concreto, de los inspectores. En efecto, antes de la modificación introducida por la Ley Foral 6/2010, la inspección debía comprobar antes de iniciarse la actividad, la veracidad de lo señalado por los prestadores para controlar su adecuación a la normativa. En este sentido, tenían una gran responsabilidad ya que hasta que ellos decidieran el particular no podía empezar la actividad.

Lo que más llama la atención es que, siendo significativo el cambio que se ha producido en la actuación de los inspectores, este no se ha reflejado en la legislación foral. En la actualidad, las inspecciones se llevan a cabo con posterioridad a la presentación de la declaración responsable. La visita de inspección se realiza con el fin de otorgar una resolución para que la actividad pueda ser inscrita en el Registro, pero el particular ya no tiene que esperar a la decisión de los inspectores para iniciarla.

${ }^{90}$ Véase a este respecto el art. 26.1 del texto refundido de la Ley de Turismo de Aragón, aprobada mediante Decreto Legislativo 1/2013, de 2 de abril, del Gobierno de Aragón, que exige autorización turística previa para el inicio de la actividad en relación con la apertura de complejos turísticos, la realización de actividades de turismo activo y el establecimiento de alojamientos turísticos al aire libre. 
Sin embargo, este nuevo modelo de inicio de actividad que sacrifica la intervención previa de la administración en aras a la máxima agilidad en la prestación del servicio, también puede plantear problemas importantes. Existen prestadores que presentan la declaración responsable sin cumplir gran parte de los requisitos señalados en la misma, lo que provoca numerosas visitas de inspección y consumo de recursos. Se da incluso el caso, no infrecuente, de establecimientos en los que el proceso de subsanación de deficiencias dura años y es compatible con el mantenimiento de la actividad.

Por ello, sería conveniente que la legislación contemplase mecanismos para que los prestadores de servicios turísticos, presentasen su declaración responsable con las máximas garantías de que la actividad cumple los requisitos necesarios para su ejercicio y estableciese un sistema ágil de actuación de la inspección, lo más cercano en el tiempo a la presentación de la declaración responsable e, incluso, simultánea, con plazos y procedimientos claros y homogéneos. Es evidente que en el nuevo modelo de control posterior, los servicios de inspección deben reorientar su labor y ejercerla con las máximas garantías en la medida en que la actividad sujeta a revisión ya se ha iniciado.

Podría recogerse también la previsión de que el prestador del servicio pudiera solicitar informes previos a la administración sobre la adecuación de su actividad a los requisitos y normas establecidos en la legislación turística, como ya recogen algunas comunidades autónomas como Aragón, Galicia y Extremadura ${ }^{91}$. Este informe previo de valoración que podría contemplarse, al menos, en el caso de actividades turísticas de cierta importancia o complejidad, ofrecería más certeza al operador turístico sobre la actividad a realizar, incrementando la seguridad jurídica de todo el proceso y dándole a conocer con antelación si su proyecto se ajusta o no a la normativa, minimizando las consecuencias que pueden derivar de los controles "ex post".

Pudiera plantearse también la posibilidad de que la Administración, cobrara un importe por la actuación de la inspección, a partir de la segunda o tercera visita, en aquellos casos en que estas sean consecuencia de un actuar negligente del prestador e, incluso, aplicar medidas sancionadoras más contundentes en el caso de prestadores que de manera reiterada no ajustan su actividad a los requisitos establecidos.

${ }^{91}$ Vid. Decreto Legislativo 1/2013, de 2 de abril, del Gobierno de Aragón, por el que se aprueba el Texto Refundido de la Ley del Turismo de Aragón, artículo 28; Ley 7/2011, de 27 de octubre, del Turismo en Galicia, artículo 49 y Ley 2/2011, de 31 de enero, de desarrollo y modernización del turismo de Extremadura, artículo 51. 
Todas estas medidas debieran complementarse con una adecuada puesta al día en la LFT de todo el régimen de infracciones y sanciones. El nuevo modelo implantado exige reforzar el régimen sancionador para que cumpla una función preventiva y, en su caso, represora de conductas o actuaciones irregulares en materia turística, en línea con otras legislaciones autonómicas ${ }^{92}$.

En definitiva, la nueva legislación debe procurar que, cuando el operador turístico presenta su declaración, la actividad reúna los requisitos necesarios para su ejercicio, reforzando al máximo las medidas preventivas, reorientando el modo de actuar de la inspección y reforzando el régimen sancionador, de modo que se garantice que la actividad turística, iniciada ahora sin un control previo, se ejerza desde el principio con plenas garantías y de manera adecuada. La garantía de un buen servicio al usuario, el ahorro de medios a la administración turística y la evitación de perjuicios al prestador una vez iniciada su actividad, requieren un nuevo enfoque de todo el proceso de supervisión y control "ex post" de la actividad.

\section{Información y formación de los operadores turísticos}

Ante el cambio de modelo operado para el ejercicio de actividades turísticas, por el que las autorizaciones previas se sustituyen por un control posterior sobre la base de una declaración responsable, es básico informar a los operadores de los requisitos que deben cumplir para ejercer su actividad, para que su declaración responsable sea correcta y el control posterior de la Administración no arroje sorpresas. El cambio de modelo hace recaer la responsabilidad en los operadores turísticos que deberán estar bien informados $\mathrm{y}$ formados en los requisitos que conlleva el correcto ejercicio de su actividad.

La DS es consciente de este cambio de modelo y sus consecuencias, e insiste en su considerando 50 en la necesidad de que los prestadores de servicios puedan acceder fácilmente a determinada información. El considerando 51, por su parte, señala que la información suministrada a los prestadores de servicios debe incluir trámites y procedimientos para el ejercicio de actividades, datos de contacto de las autoridades competentes, condiciones de acceso a bases de datos públicos, sistemas de recursos y datos de entidades y asociaciones que puedan proporcionarles asistencia técnica, resaltando la obligación de las autoridades competentes de informar sobre el modo en que suelen interpretarse o aplicarse los requisitos.

92 Vid. a este respecto, el art. 78 de la Ley 13/2011, de 23 de diciembre, del Turismo de Andalucía; art. 94 de la Ley 13/2002, de 21 de junio, de Turismo de Cataluña y los arts. 100 y 101 del Anteproyecto de Ley de Turismo del País Vasco, de 13 de febrero de 2015. 
Junto a estas obligaciones concretas de la Administración de prestar información a los operadores turísticos, que la legislación turística debiera recoger, sería deseable que esa legislación contemplara también, medidas o acciones concretas de formación de esos operadores en las materias que afecten al ejercicio de su actividad. Ello propiciaría una relación más cercana entre la administración y los prestadores de servicios; garantizaría en mayor medida el correcto ejercicio de la actividad e incidiría en una mejor calidad del servicio y del grado de satisfacción de los usuarios. Asímismo, ofrecería mayores garantías y seguridad jurídica al operador turístico a la hora del control por la inspección de las actividades, ya que estos podrían conocer mejor los aspectos sujetos a ese control y el modo en que van a ser evaluados.

\section{6.- Apuesta por la calidad, el turismo sostenible y el enfoque hacia el usuario de los servicios turísticos}

Calidad del servicio, turismo sostenible y enfoque hacia el usuario, son tres conceptos que, en materia turística, están estrechamente ligados. Por ello, uno de los grandes objetivos de la DS y de la LFT es la apuesta clara por la calidad. La DS dedica a esta cuestión su capítulo $\mathrm{V}$, recogiendo una serie de medidas concretas que van desde la necesidad de que los prestadores pongan a disposición de los usuarios información detallada sobre la actividad que desarrollan (art. 22.1), pasando por la necesidad de que cuenten con seguros de responsabilidad que cubran posibles eventualidades (art. 23.1) y el sometimiento de los operadores a sistemas de certificación o evaluación por organismos independientes acreditados (art. 26.1), hasta el establecimiento de cauces para que los operadores turísticos den respuesta en el plazo más breve y con la máxima diligencia a las reclamaciones que los usuarios les puedan plantear (art. 27).

Debe destacarse que la Comunidad Foral, siendo la apuesta por la calidad una línea prioritaria de actuación marcada por la DS, no introdujo en la normativa de transposición ninguna modificación relacionada ella y que, en la práctica, tampoco se ha marcado una línea clara de actuación al respecto. Por ello la futura regulación legal del turismo debiera incorporar medidas concretas en línea con las pautas señaladas por la Directiva, especialmente, con el desarrollo de sistemas ágiles de tramitación de quejas y reclamaciones ante la propia administración turística, más allá de la posibilidad ya prevista en el artículo $31 \mathrm{~g}$ ) de la LFT de recurrir a la Junta Arbitral de Consumo. La LFT contempla como un derecho de los usuarios la posibilidad de presentar 
reclamaciones y quejas contra los operadores turísticos, sin embargo, nada señala en relación con el procedimiento a seguir a la hora de tramitar esas quejas.

Otro modo dar cumplimiento a las directrices indicadas por la DS sería, establecer la obligación legal de realizar un seguimiento periódico de las instalaciones y actividades turísticas que existen actualmente en Navarra. La inspección de turismo actúa, por lo general, antes de la firma de la resolución y la consiguiente inscripción en el Registro. Una buena forma de mejorar la calidad de los servicios turísticos sería que los inspectores, comprobasen en los plazos señalados por la legislación la situación de los alojamientos que en su día autorizaron. Existen muchos establecimientos que se inscribieron cumpliendo las condiciones señaladas por la ley en su día, que en la actualidad han quedado obsoletos y actualmente no cumplen la normativa y, salvo que medie reclamación, no se comprueban las condiciones de dichos establecimientos.

Como he señalado, en el ámbito del turismo, calidad del servicio y turismo sostenible, están estrechamente unidos, especialmente, en una Comunidad como Navarra en la que muchas de las actividades turísticas están ligadas al entorno natural. Por ello su protección es otra de las prioridades que la futura regulación foral del turismo debiera tener en cuenta, estableciendo medidas concretas de preservación y trabajando estrechamente con otras áreas de la administración como la medioambiental.

Entre las medidas que desde el punto de vista de la legislación turística podrían adoptarse para lograr un turismo sostenible, podemos señalar la exigencia de controles administrativos previos más rigurosos para el ejercicio de actividades que incidan de manera importante en el medioambiente; establecer límites en la utilización del medio natural para las actividades que se desarrollan en el mismo; realizar controles periódicos sobre el modo en que la actividad se lleva a cabo o regular la responsabilidad de las empresas turísticas en cuanto a las afecciones que su actividad genera y su reparación.

En todo caso, en unos momentos en que las actividades relacionadas con el disfrute del medio ambiente y el número de usuarios de las mismas, crece sin cesar, entiendo que la legislación turística tiene que incorporar medidas claras de protección de los recursos naturales y del medio ambiente.

\section{7.- Apuesta por la administración electrónica y la simplificación administrativa.}

Otra de las líneas claras de actuación de la DS a la que dedica su Capítulo II, es la simplificación administrativa, contemplando medidas como la simplificación de procedimientos (art. 5), la ventanilla única (art. 6), el establecimiento de sistemas ágiles 
de información (art. 7) o la utilización de los procedimientos electrónicos (art. 8). Tampoco en este punto la transposición efectuada en Navarra, en el ámbito del turismo, ha adoptado medidas concretas, si bien la Comunidad Foral cuenta con la Ley Foral 11/2007, para la implantación de la Administración Electrónica y con la ya citada Ley Foral 15/2009, de medidas de simplificación administrativa para la puesta en marcha de actividades empresariales o profesionales, que también contempla medidas en esta dirección.

La DS apuesta por la tramitación telemática de los procedimientos. En este sentido, la Ley Foral 6/2010, no introdujo ninguna modificación al respecto en materia de turismo, limitándose a señalar que el prestador debía presentar una declaración responsable para la inscripción en el Registro. En sintonía con los objetivos de la DS, sería conveniente apostar por la vía electrónica. Para ello, debería crearse una plataforma telemática a través de la cual los prestadores pudieran presentar sus declaraciones y documentos. Ello simplificaría los trámites, lograría un importante ahorro de medios (en la actualidad todas las declaraciones responsables están en papel) y la Administración tendría un control más efectivo de los prestadores de servicios turísticos de la Comunidad Foral. Las declaraciones responsables, junto con los respectivos documentos, se encontrarían en la plataforma y la Administración telemáticamente comprobaría con rapidez y exactitud la adecuación de los prestadores a la normativa vigente. También, supondría una ventaja para los prestadores ya que podrían consultar los trámites necesarios para poner en marcha su actividad y podrían obtener respuesta de las consultas que pudieran tener.

En el ámbito medioambiental, la Orden Foral 448/2014, de 23 de diciembre, ha introducido este modo de proceder. Así su artículo 16.2 indica que "la declaración responsable se deberá realizar a través del servicio telemático habilitado en el Catálogo de Servicios del Gobierno de Navarra o, en caso de no encontrarse disponible, a través del Registro General Electrónico del Gobierno de Navarra"93.

Por lo que respecta a otras medidas de simplificación administrativa, la legislación turística debiera recoger otro tipo de iniciativas en línea con las previsiones de la DS, actualizando y regulando los formularios de las actuaciones turísticas básicas, como las

${ }^{93}$ Así el Art.14.2 de la OF 448/2014 dispone que "La documentación estará firmada por técnico competente, y se presentará en soporte digital a través del Registro General electrónico del Gobierno de Navarra o de Consigna de Proyectos del Gobierno de Navarra. Esta última opción será obligatoria para proyectos mayores del tamaño al que esté limitado el Registro General electrónico del Gobierno de Navarra". 
declaraciones responsables o las hojas de reclamaciones y quejas, y reduciendo los plazos de las actuaciones de la administración turística.

\section{8.- Cooperación y coordinación entre administraciones públicas}

Los artículos 28 a 38 de la DS establecen la relevancia de la cooperación administrativa entre los Estados miembros, a fin de lograr un mercado interior de servicios. Sin embargo, considero que para que exista una cooperación recíproca entre los Estados miembros, es necesario que previamente exista una interconexión entre las Administraciones públicas del propio Estado y, en nuestro caso, de la Comunidad Foral. Tras la DS, aunque la cooperación entre las Administraciones Públicas en el ámbito del turismo ha evolucionado, nos encontramos alejados de una interconexión más eficiente que beneficiaría a la Administración y también a los propios ciudadanos.

El principio de cooperación está recogido en el artículo 4 de la LFT, lo que demuestra su importancia. Pese a ello, la práctica demuestra que hacen falta mecanismos legales o reglamentarios que articulen esta cooperación y coordinación tan necesaria, en un ámbito en el que las distintas Administraciones están interrelacionadas.

Señalaré a modo de ejemplo, que el Departamento de Turismo, en virtud del artículo 14.7 de la Ley Foral 7/2003, tiene competencia para cancelar de oficio una inscripción: "El cese de la actividad para la que se ha practicado la inscripción durante un periodo superior a dos años consecutivos, conllevará la cancelación de oficio de la inscripción practicada”. Por tanto, si durante dos años consecutivos, un establecimiento o actividad turística ha estado cerrado, podrá decretarse la baja de oficio. El modo más directo para conocer este hecho es analizar si la actividad ha estado de alta en el impuesto de actividades económicas. Hasta hace poco, algunos ayuntamientos de Navarra se negaban a facilitar los datos al Departamento alegando que la información la habían enviado a Hacienda y que no tenían la obligación de volverla a enviar a Turismo. En la actualidad, este problema se ha superado y desde el Departamento de Turismo se puede acceder a la base de datos de la Hacienda Foral para conocer estos datos.

Sería conveniente que la coordinación que se ha logrado con Hacienda se consiguiese también en otros ámbitos. En las declaraciones responsables que presentan los interesados, existe un apartado que consiste en señalar que los prestadores, cuentan con las correspondientes licencias municipales, por lo que el Gobierno de Navarra, en caso de que quiera comprobar que la documentación presentada es cierta, debe ponerse en contacto con los Ayuntamientos. No existe un enlace en el que se pueda comprobar 
la información y considero que el Departamento de Turismo debería tener acceso a esa documentación, ya que supondría un gran avance.

Destacar que, tanto la Ley 11/2007, de 22 de junio, de Acceso Electrónico de los Ciudadanos a los Servicios Públicos (artículos 41 y siguientes), como la Ley Foral 11/2007, de 4 de abril, para la Implantación Electrónica en la Administración de la Comunidad Foral (d.a. cuarta), ya establecían que las administraciones públicas en sus relaciones entre ellas y con los ciudadanos deben garantizar el máximo nivel de interoperabilidad y que, la nueva Ley 40/2015, de 1 de octubre de 2015, de Régimen Jurídico del Sector Público, destaca como nuevo principio que debe presidir la actuación de las Administraciones Públicas el de la interoperabilidad (artículo 3.2), según el cual las AAPP se relacionarán entre sí a través de medios electrónicos y sistemas que garanticen el máximo nivel de interrelación entre ellas.

En definitiva, sería deseable que la nueva regulación turística articulase mecanismos legales y reglamentarios concretos de coordinación y cooperación entre las Administraciones implicadas en materia de turismo, en todos aquellos aspectos en los que pueda darse esa interconexión y en los que esa colaboración redunde en beneficio de todos los implicados en la actividad turística.

\section{9.- Respuesta a los nuevos retos y realidades del sector turístico}

Como he señalado, el turismo es una parte esencial del sector servicios, con un importante potencial de crecimiento, que tiene un comportamiento muy dinámico y en constante evolución. Por ello considero que la plena transposición de la DS también exige incorporar al nuevo marco jurídico, como están haciendo otras Comunidades Autónomas $^{94}$, las nuevas figuras y realidades turísticas en la medida en que, tanto la Administración, como los prestadores de servicios y los usuarios, deben tener un marco seguro de actuación y unas referencias claras sobre cómo debe actuarse en cada caso. En este sentido, la reforma de la LFT debe abordar también estas materias.

Así, todo lo relacionado con el ecoturismo, el turismo activo y de aventura, tan de moda en nuestra Comunidad, que incide notablemente en el medio natural y afecta a derechos básicos de los usuarios como la seguridad por el riesgo que entrañan, debieran

\footnotetext{
${ }^{94}$ Vid. a este respecto el texto refundido de la Ley de Turismo de Aragón, cit., arts. 35 y siguientes; Anteproyecto de Ley de Turismo del País Vasco, cit., arts. 39 y siguientes.
} 
ser objeto de una regulación más amplia que ahora se limita a su mención en el art. 28 de la LFT.

Otras realidades tan diferentes pero que también están ganando terreno en los últimos tiempos, como las zonas de servicios para auto caravanas, las zonas de acampada libre o las zonas de acampada temporal con motivo de eventos de todo tipo, también debieran ser objeto de atención preferente por el legislador foral teniendo en cuenta sus afecciones al entorno natural y a la seguridad de las personas.

Existe todo un bloque de actividades relacionada con nuevas figuras de alojamiento, como la oferta de viviendas para uso turístico, la de habitaciones individuales con el mismo fin, la oferta al público de habitaciones en residencias de estudiantes o colegios mayores o el intercambio de viviendas con fines vacacionales, que también debieran ser reguladas en la legislación turística, por incidir notablemente en el sector y poder suponer competencia desleal para los alojamientos tradicionales.

La legislación turística también debiera contemplar la oferta de recursos turísticos por personas que no son profesionales del sector, ni se dedican habitualmente a él, pero que pueden generar actividad económica. Pensemos en los alquileres de balcones en San Fermín que pueden incluir alojamiento y desayuno, o en servicios de agroturismo prestados puntualmente por agricultores o ganaderos, por poner solo dos ejemplos.

También debieran contemplarse las profesiones turísticas y las nuevas formas de mediación y contratación de servicios turísticos, realizadas más allá de las agencias de viaje, mediante centrales de compras, centrales de reservas y portales en internet cuya regulación, aunque compleja, debiera abordarse siguiendo las pautas de la Directiva.

Por último, señalar que existen otra serie de empresas de servicios y de iniciativas cuya actividad, sin ser propiamente turística, tiene una repercusión importante en el sector turístico, como pueden ser las relativas a la organización de congresos y seminarios, de eventos culturales o deportivos, empresas de transporte e iniciativas de divulgación de valores patrimoniales o naturales, que por su interés para el sector debieran también ser objeto de atención prioritaria en la nueva regulación del turismo.

La reforma de la LFT debiera proceder también a una puesta al día general de su preámbulo y articulado, con mención expresa a la DS y a sus principios de actuación, así como actualizar las definiciones turísticas. Así mismo debería definir con claridad la libertad de establecimiento y la libre prestación de servicios, así como el régimen 
aplicable a cada una partiendo de que la diferencia fundamental radica en si el prestador del servicio turístico está o no establecido en el Estado miembro ${ }^{95}$.

${ }^{95}$ Vid. PÉREZ FernÁnDEZ, J.M. “Directiva de Servicios y Turismo (...)”, cit., pág. 257, afirma: “el elemento clave para distinguir entre libertad de establecimiento y libre circulación de servicios es, como reconoce expresamente el considerando 77 de la Directiva de Servicios, apoyándose en la jurisprudencia del Tribunal de Justicia de la Unión Europea, si el prestador del servicio turístico está o no establecido en el Estado miembro en el que presta el servicio de que se trate:

1. Si está establecido en el Estado miembro, está dentro del ámbito de libertad de establecimiento.

2. Si no está establecido en el Estado miembro en el que presta sus servicios, sus actividades deben quedar cubiertas por la libre circulación de servicios". 


\section{VI.- CONCLUSIONES}

Primera. Ante la constatación de que el mercado interior de servicios no era una realidad en el ámbito de la Unión, por las trabas y barreras establecidas por los Estados miembros, el Parlamento y el Consejo Europeo aprobaron en 2006 la DS con el fin de crear ese mercado interior, que hiciera realidad la libertad de establecimiento y la libre circulación de servicios, proclamadas por el Tratado de la Unión desde 1958.

Segunda. La DS se presenta como una gran oportunidad para que los Estados miembros modernicen el sector servicios mediante la eliminación de controles y barreras, lo que mejorará la eficiencia y la calidad de los servicios prestados y la atención a los operadores y usuarios. Por su impacto en los ordenamientos jurídicos de los países miembros, puede señalarse que la DS es la norma comunitaria más importante aprobada en la Unión Europea desde su creación.

Tercera. La transposición de la DS a la Comunidad Foral en materia turística, se ha efectuado mediante la modificación que el artículo 5 de la Ley Foral 6/2010 ha introducido, fundamentalmente, en los arts. 13, 14 y 26 de la Ley Foral 7/2003 del Turismo, que ha tenido continuación reglamentaria en el Decreto Foral 10/2011, de modificación de diversos reglamentos en materia de turismo. En esencia, esta reforma se ha limitado a sustituir el régimen de autorización administrativa previa para el ejercicio de actividades turísticas, por el de libre ejercicio basado en una declaración responsable del operador turístico, que conlleva la inscripción automática por la Administración en el Registro de Turismo de Navarra, sin perjuicio de los controles posteriores que se puedan llevar a cabo.

Cuarta. Siendo la DS una norma comunitaria de extraordinaria importancia y que contempla múltiples medidas para modernizar y dinamizar el sector de los servicios, considero que la transposición efectuada en la Comunidad Foral en materia de Turismo, aunque importante, ha sido muy limitada e incompleta, al haberse centrado en un único aspecto, no habiéndose aprovechado la oportunidad para reformar en profundidad la Ley Foral 7/2003 de Turismo, siguiendo las líneas de actuación marcadas por la DS, y para dotar a Navarra de un nuevo marco jurídico completo que regule este sector tan dinámico e importante para la Comunidad Foral.

Quinta. La reforma de la LFT es prioritaria en estos momentos para incorporar plenamente el cambio de modelo que la DS plantea, que va mucho más allá de la mera introducción de la declaración responsable como factor de inicio de la actividad turística y debe conllevar una transformación profunda de los factores que intervienen en la 
actividad: el operador turístico, la Administración, la actividad o servicio turístico y el usuario. Este cambio de modelo exige incidir, de manera conjunta y coordinada, en cuestiones como la responsabilidad del operador turístico, su nivel de información y formación, el nuevo papel que corresponde a la Administración Turística y a sus servicios de inspección, la calidad y sostenibilidad de la actividad, el régimen sancionador, la atención preferente al usuario, la simplificación de trámites y procedimientos y la coordinación entre las Administraciones implicadas. Asimismo la reforma de la LFT debe aprovecharse para regular las nuevas realidades turísticas y dar respuesta a los problemas planteados con la actual regulación, a la luz de la experiencia de los más de doce años de aplicación.

Sexta. Como aspectos concretos que la futura Ley Foral de Turismo debiera contemplar, podemos señalar los siguientes:

$1^{\mathrm{a}}$.- La regulación detallada y ordenada de los elementos que inciden en el inicio de la actividad turística como la propia declaración responsable, la inscripción en el Registro de Turismo, la actuación de control de la Administración sobre la corrección de la declaración presentada y las consecuencias sancionadoras que puedan derivarse de ella. $2^{\mathrm{a}}$.- La recuperación de la autorización administrativa previa, cuando concurran razones de interés general, respecto de las que el control posterior de la actividad pueda resultar tardío o insuficiente.

$3^{\mathrm{a}}$.- El establecimiento de medidas preventivas como el informe previo de adecuación de la actividad a los requisitos exigidos y la información permanente a los operadores turísticos, tendentes a que la actividad turística se realice desde su inicio de acuerdo con los requisitos establecidos.

$4^{\mathrm{a}}$.- La redefinición de la función comprobadora e inspectora de la administración reorientada al control posterior que ahora se le asigna, así como la puesta al día y reforzamiento del régimen de infracciones y sanciones.

5 a - La apuesta clara por la calidad, el turismo sostenible y la atención preferente a los usuarios, estableciendo instrumentos concretos siguiendo las líneas propuestas por la DS, como sistemas ágiles de tramitación administrativa de reclamaciones y quejas, seguimiento periódico de las actividades o control de afecciones medioambientales.

$6^{\text {a }}$ - El establecimiento de medidas de simplificación y agilización administrativa, como la reducción de plazos, la armonización y actualización de formularios, o la puesta en marcha de plataformas telemáticas de presentación de documentos. 
$7^{\mathrm{a}}$.- La articulación de mecanismos concretos de coordinación y cooperación de las Administraciones implicadas en materia de turismo, en todos aquellos aspectos en los que la interconexión de bases de datos y registros pueda resultar de interese recíproco. $8^{\text {a }}$ - La incorporación de las nuevas figuras turísticas surgidas con fuerza en los últimos años como el turismo activo y de aventura, las nuevas forma de acampada, las zonas de servicios para auto caravanas, la oferta de viviendas y habitaciones con fines turísticos, la prestación no habitual de servicios turísticos por particulares o profesionales de otros sectores, las nuevas formas de mediación turística a través de centrales de reserva o portales de internet y la atención preferente a iniciativas no propiamente turísticas, pero que pueden repercutir en el sector, entre otras.

$9^{a}$.- Por último, Ley Foral del Turismo debiera proceder a una puesta al día general de su preámbulo y articulado, con mención directa a la DS, a sus principios y líneas de actuación, así como a sus definiciones de los conceptos turísticos. 


\section{BIBLIOGRAFÍA}

BAUZÉ MARTORELL, F. J. en la comunicación sobre "la incidencia de la Directiva de Servicios sobre la Legislación de Turística. Estudio Autonómico comparado", recogida en el libro Turismo y Desarrollo Económico: IV Jornadas de Investigación en Turismo, organizadas por la Facultad de Turismo y Finanzas de la Universidad de Sevilla, que recoge las diversas comunicaciones presentadas a las mismas (Sevilla 4-2011).

BERMEJO LATRE, J.L. y ESCARTÍN ESCUDÉ, V. "El impacto de la reforma de servicios en el sector del turismo", en Revista Aragonesa de Administración Pública, Zaragoza, 2010, en Monografía sobre el impacto de la directiva Bolkestein y la reforma de los servicios en el derecho administrativo.

CORRAL SASTRE, A. "Libre prestación de servicios y calidad turística. Los efectos de la liberalización del sector", Madrid, Tesis Doctoral, año 2013.

ESTEVE GARCÍA, F. "Els diferents instruments de liberalitzazió inclosos en la Directiva 2006/123 de serveis”, en Revista Catalana de Dret Públic, núm. 42, 2011.

FERNÁNDEZ BARJAU, B. Y MARTÍNEZ ALBALADEJO, T. "El proceso de transposición de la Directiva de Servicios en España", en Boletín Económico de ICE. Información Comercial Española, núm. 2990, 2010.

FERNÁNDEZ RODRÍGUEZ, T.R. "Un nuevo Derecho Administrativo para el mercado interior europeo", en Revista Española de Derecho Europeo, núm. 22, 2007.

GÓMEZ ALONSO, M. y ÁLVAREZ BESTEIRO, I. "Principales reformas sectoriales: consolidación de la nueva cultura regulatoria", en Boletín Económico del ICE, núm. 2990, del 1 al 15 julio de 2010.

JIMÉNEZ ASENSIO, R. La incorporación de la DS al Derecho interno. Instituto Vasco de Administración Pública, IVAP, Oñati, 2010.

LÓPEZ MENUDO, F. "La transposición de la Directiva de Servicios y la modificación de la Ley 30/1992: el régimen de la declaración responsable y de la comunicación previa", en Revista Española de la Función Consultiva, núm. 14, 2010. 2005.

MESSERLIN, P.A. "The Directive on Services: Rent seekers strike back” en Intereconomics,

MUÑOZ MACHADO, S. "Ilusiones y conflictos derivados de la Directiva de Servicios", en Revista General de Derecho Administrativo, núm. 21, 2009.

PAREJO ALFONSO, L.J. "La Directiva Bolkestein y la Ley paraguas: ¿legitima el fin cualesquiera medios para la reconversión del Estado 'autoritativo'?", en Revista Española de Derecho Europeo, núm. 32, 2009.

PÉREZ FERNÁNDEZ, J.M. "Directiva de servicios y turismo: el nuevo régimen de acceso y prestación de los servicios turísticos y su contribución al incremento de la calidad turística", en Revista de Derecho de la Unión Europea, núm. 24, 2013.

RAZQUIN LIZARRAGA, J.A. "El impacto de la Directiva de Servicios en el procedimiento administrativo: Autorización, Declaración responsable y comunicación”, en Revista Jurídica de Navarra, núm. 49, 2010.

RAZQUIN LIZARRAGA, M M $\mathrm{M}^{\mathrm{a}}$. "La ordenación jurídica del turismo en navarra", en Revista Jurídica de Navarra, núm. 35, 2003. 
RODRÍGUEZ FONT, M. "La contribución inicial de la jurisdicción contencioso-administrativa a la construcción del régimen de control a posteriori (comunicación previa y declaración responsable)", en Revista Andaluza de Administración Pública, núm. 90, 2014.

SALVADOR ARMENDÁRIZ $\mathrm{M}^{\mathrm{a}}$ A. "Directiva de Servicios y Administración local: cuestiones generales de su transposición en Navarra" en Revista Jurídica de Navarra, núm. 52, 2011.

VILLAREJO GALENDE, H. y SALVADOR ARMENDÁRIZ, M.A. "El complejo proceso de transposición de la Directiva de Servicios", en Informe Comunidades Autónomas 2008, Instituto de Derecho Público, Barcelona 2009. 